\title{
Arachidonate 15-lipoxygenase is required for chronic myeloid leukemia stem cell survival
}

\author{
Yaoyu Chen, ${ }^{1}$ Cong Peng, ${ }^{1}$ Sheela A. Abraham, ${ }^{2,3}$ Yi Shan, ${ }^{1}$ Zhiru Guo,, ${ }^{1}$ Ngoc Desouza, ${ }^{1}$ Giulia Cheloni, ${ }^{1,4}$ Dongguang Li, ${ }^{5}$ \\ Tessa L. Holyoake, ${ }^{2}$ and Shaoguang $\mathrm{Li}^{1}$ \\ Division of Hematology/Oncology, Department of Medicine, University of Massachusetts Medical School, Worcester, Massachusetts, USA. Institute of Cancer Sciences, College of Medical, Veterinary and \\ Life Sciences, University of Glasgow, Glasgow, United Kingdom. ${ }^{3}$ School of Cancer and Enabling Sciences, University of Manchester, Manchester, United Kingdom. ${ }^{4} \mathrm{Dipartimento}$ di Scienze Biomediche, \\ Sperimentali e Cliniche Mario Serio, Università degli Studi di Firenze, Firenze, Italy. ${ }^{5}$ School of Computer and Security Science, Edith Cowan University, Mount Lawley, Perth, Australia.
}

\begin{abstract}
Cancer stem cells (CSCs) are responsible for the initiation and maintenance of some types of cancer, suggesting that inhibition of these cells may limit disease progression and relapse. Unfortunately, few CSC-specific genes have been identified. Here, we determined that the gene encoding arachidonate 15-lipoxygenase (Alox15/15-LO) is essential for the survival of leukemia stem cells (LSCs) in a murine model of BCR-ABL-induced chronic myeloid leukemia (CML). In the absence of Alox15, BCR$A B L$ was unable to induce $C M L$ in mice. Furthermore, Alox15 deletion impaired LSC function by affecting cell division and apoptosis, leading to an eventual depletion of LSCs. Moreover, chemical inhibition of 15-LO function impaired LSC function and attenuated CML in mice. The defective CML phenotype in Alox15-deficient animals was rescued by depleting the gene encoding P-selectin, which is upregulated in Alox15-deficient animals. Both deletion and overexpression of P-selectin affected the survival of LSCs. In human CML cell lines and CD34+ cells, knockdown of Alox15 or inhibition of 15-LO dramatically reduced survival. Loss of Alox15 altered expression of PTEN, PI3K/AKT, and the transcription factor ICSBP, which are known mediators of cancer pathogenesis. These results suggest that ALOX15 has potential as a therapeutic target for eradicating LSCs in CML.
\end{abstract}

\section{Introduction}

Cancer stem cells (CSCs) in a variety of hematologic malignancies and some solid tumors are required for cancer initiation and are responsible for disease relapse (1-7). Accumulating evidence suggests that CSCs must be targeted to achieve effective and curative therapies for these malignant diseases. A number of genes have been shown to regulate CSC proliferation, including $W n t / \beta$-catenin, Hedgehog, Notch $(3,4,8-11), \operatorname{Bim1}(12,13), p 53(8), 1^{\text {INK4a }}(14)$, p19 ${ }^{A R F}$ (15), Pten (16), PML (17), PP2A (18), Alox5 (19), TGFB/FOXO (20), and Musashi (21). A major challenge is to identify effective target genes for developing anti-CSC strategies in cancer treatment. Because CSCs often express similar markers and are regulated in a manner similar to that of their normal stem cell counterparts (22, 23), it is difficult to develop a therapeutic strategy aimed at selectively targeting CSCs, although Alox 5 is specifically required for the survival of leukemia stem cells (LSCs) in chronic myeloid leukemia (CML) (19). There are some examples showing that although certain genes play roles in both cancer and normal stem cells, they are functionally more critical for cancer than for normal stem cells (24, 25). In this situation, the difference in the degree of dependence on the same genes for survival between cancer and normal stem cells provides a therapeutic window for more selective killing of CSCs.

It is reasonable to believe that although the list of aberrantly expressed genes in CSCs may be extensive, there exists a selective

Authorship note: Yaoyu Chen and Cong Peng contributed equally to this work. Conflict of interest: The authors have declared that no conflict of interest exists. Submitted: August 1, 2012; Accepted: June 19, 2014.

Reference information: J Clin Invest. 2014;124(9):3847-3862. doi:10.1172/JCI66129. number of genes that play critical roles in regulating the survival of CSCs and that could be used as targets for eradicating these cells. In this study, taking advantage of our previous identification of CML LSCs in mice (26), we used BCR-ABL-induced CML as a stem cell disease model to identify effective target genes in LSCs, which have been shown to be insensitive to $B C R-A B L$ kinase inhibitors in CML mice (27) and in human $\operatorname{CML}(28,29)$. Here, we identify Alox15 as a critical regulatory gene for LSC survival. We show that Alox15 deficiency or inhibition of the function of this gene causes the depletion of LSCs and prevents the initiation of $B C R-A B L$-induced CML in mice. Alox15 encodes arachidonate 15-lipoxygenase (15-LO). Compared with Alox5, which we identified previously (19), Alox15 has similar but also distinct functions that are involved in numerous physiological and pathological processes, including bone development (30), regulation of inflammation and immune response (31), and inhibition of proliferation/ survival of malignant cells $(32,33)$. Thus, it is unlikely that there is a complete functional redundancy between Alox 5 and Alox 15 in the maintenance of LSCs.

\section{Results}

Alox15 is required for $C M L$ induction by BCR-ABL. Because LSCs in $C M L$ are insensitive to $B C R-A B L$ kinase inhibitors (28) and $B C R$ $A B L$ kinase activity is not involved in all signaling pathways activated by $B C R-A B L(26)$, we hypothesized that there is a group of genes whose expression is regulated by $B C R-A B L$ but not restored by inhibition of $B C R-A B L$ kinase activity with imatinib. To identify these genes in LSCs, we previously conducted a DNA microarray study (GEO GSE10912), in which we isolated total RNA from bone 
A

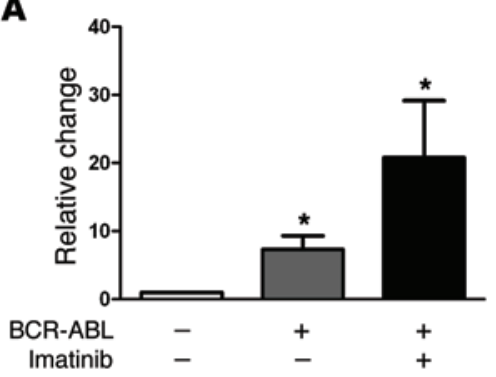

B

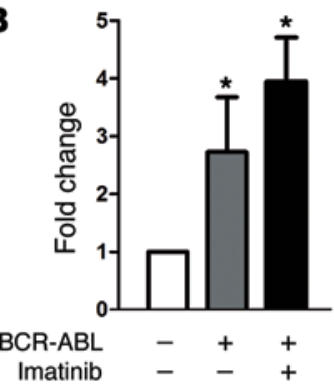

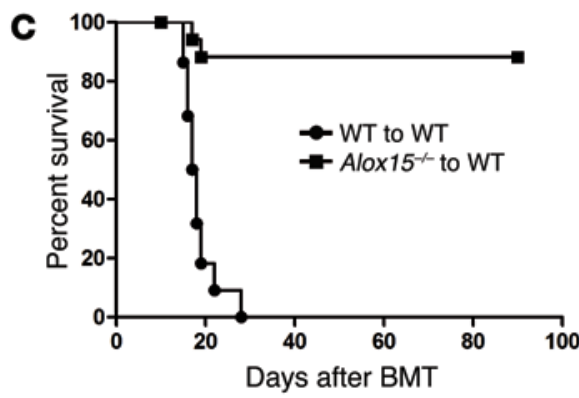

D

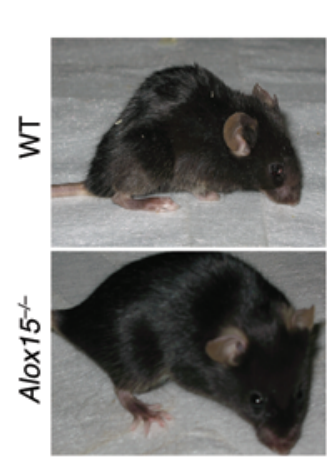

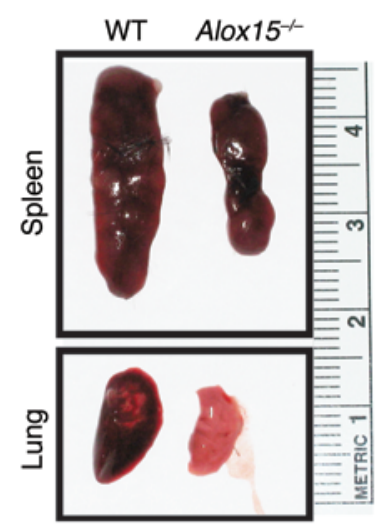
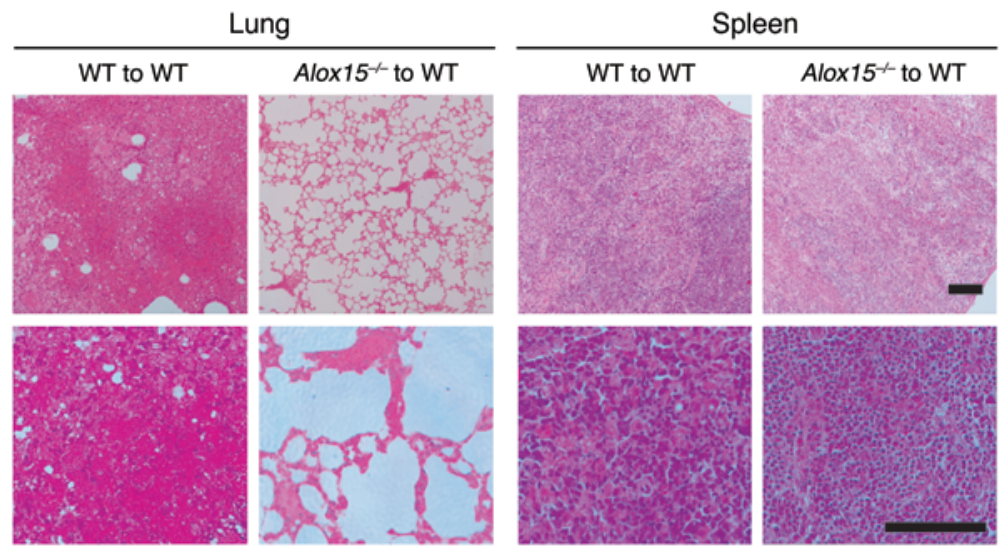

E Day $14 \quad$ Day $20 \quad$ Day $30 \quad$ Day $50 \quad$ Day $70 \quad$ Day 140
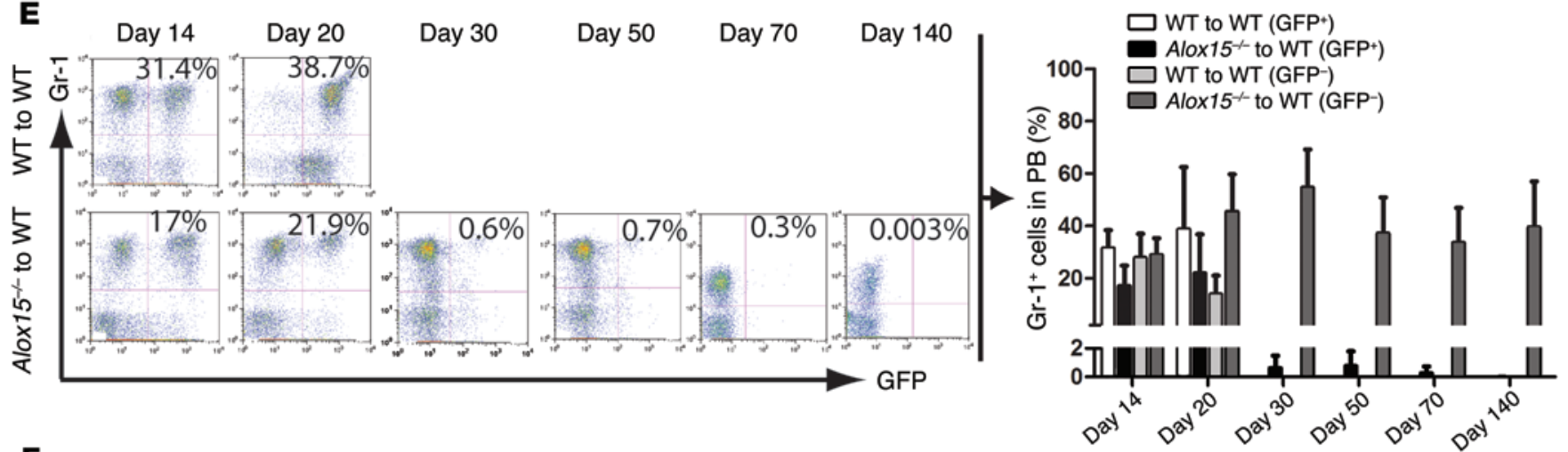

$\mathbf{F}$
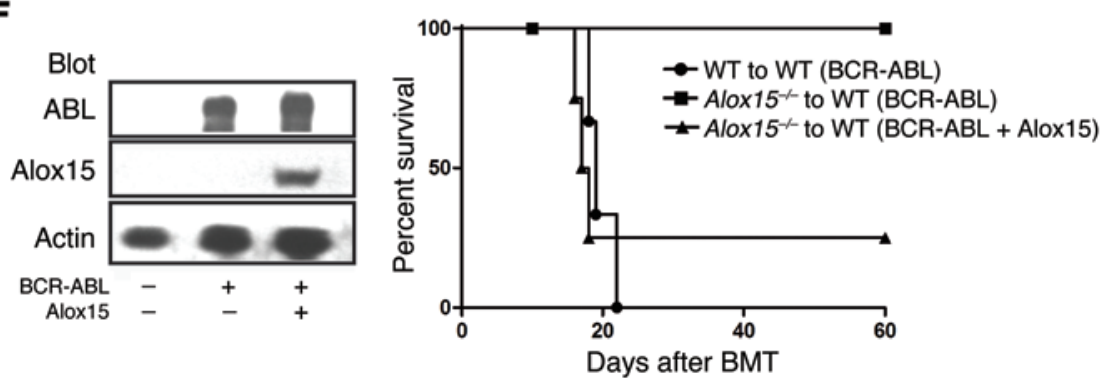

Figure 1. Alox15 is essential for CML induction by BCR-ABL. (A) DNA microarray analysis showed upregulation of $A$ lox 15 expression by $B C R-A B L$ in LSCs compared with GFP+Lin-Sca-1+c-Kit cells, which only expressed GFP, and this upregulation was not inhibited by imatinib. Results represent the mean \pm SD ( ${ }^{*} P<0.05$ ). (B) RT-PCR confirmed the upregulation of Alox15 expression by BCR-ABL in LSCs in the presence and absence of imatinib treatment $\left({ }^{*} P<0.05\right)$. Results represent the mean \pm SD. (C) Kaplan-Meier survival curves for recipients of $B C R$ - $A B L$-transduced BM cells from WT or Alox $15^{-1-}$ mice (8 mice per group). (D) Left: Gross appearance of CML mice, lung, and spleen of recipients of $B C R$ - $A B L$-transduced BM cells from WT and Alox $15^{-1-}$ donor mice. Right: Photomicrographs of H\&E-stained lung and spleen sections from recipients of $B C R$ - $A B L$-transduced BM cells from WT or Alox15 ${ }^{-1-}$ donor mice. Original magnification, $\times 10$ (top), $\times 40$ (bottom). (E) In the absence of Alox15, the percentage of GFP $\mathrm{C}^{+} \mathrm{Gr}-1^{+}$cells in PB started to decrease from day 20 and gradually disappeared after 50 days, whereas the GFP- Gr-1+ cells that did not express $B C R$ - $A B L$ increased. Results represent the mean \pm SD for each group $(n \geq 5)$. (F) Alox15 transgene rescues the defective CML phenotype. BCR-ABL and Alox15 were coexpressed in Alox15 1 - BM cells by retroviral transduction, followed by transplantation of the transduced cells into recipient mice. Left: BCR-ABL and $15-\mathrm{LO}$ were detected by Western blotting using antibodies against ABL and 15-LO in cells transfected with BCR-ABL-IRES-Alox15-pMSCV. Right: Kaplan-Meier survival curves for recipients of BCR-ABL-IRES-Alox15-pMSCV-transduced BM cells from Alox15 ${ }^{-1-}$ donor mice. 
marrow (BM) LSCs $\left(\mathrm{GFP}^{+} \mathrm{Lin}^{-} \mathrm{Sca}-1^{+} \mathrm{c}-\mathrm{Kit}^{+}\right)$in $\mathrm{CML}$ mice treated or untreated with imatinib and compared gene expression profiles between LSCs and normal hematopoietic stem cells (HSCs). The study led to our identification of the Alox 5 gene (19). In this study, we attempted to identify other critical genes in LSCs by starting with in-depth analysis of the DNA microarray data. Besides Alox5, another gene upregulated by $B C R-A B L$ in LSCs was Alox15, and its upregulation was not inhibited by imatinib treatment (Figure 1A). The upregulation of Alox15 by BCR-ABL in LSCs with and without imatinib treatment was confirmed by real-time PCR (RT-PCR) (Figure 1B). These results imply that Alox15 is involved in the regulation of LSC function by $B C R-A B L$.

To begin to examine whether Alox15 regulates the function of LSCs, we first tested the requirement of Alox 15 for CML induction by BCR-ABL using Alox15 homozygous knockout (Alox15/-) mice. Mice receiving $B C R-A B L$-transduced WT BM cells developed and died of CML within 4 weeks, whereas mice receiving $B C R-A B L-$ transduced Alox $15^{-/-}$BM cells were severely defective in their ability to induce CML (Figure 1C), which was not related to viral transduction efficiency (Supplemental Figure 1; supplemental material available online with this article; doi:10.1172/JCI66129DS1). The failure of CML development in the absence of Alox15 correlated with a healthier physical appearance of the mice and much less infiltration of leukemia cells in the lung and spleen (Figure 1D). In addition, FACS analysis of $B C R-A B L$-expressing $\left(\mathrm{GFP}^{+}\right)$myeloid $\left(\mathrm{Gr}-1^{+}\right)$cells showed that in the absence of Alox15, there was a transient growth of leukemia cells in peripheral blood (PB), but the number of these cells gradually declined to an undetectable level (Figure 1E). In the same animal, we observed a much smaller number of leukemia cells $\left(\mathrm{GFP}^{+}\right)$than nonleukemia cells $\left(\mathrm{GFP}^{-}\right)$ (Figure 1E), suggesting that Alox15 signaling in maintaining LSC survival is much more critical for LSCs than for normal HSCs in vivo. To confirm the role of Alox 15 in CML development, we conducted a rescue experiment by retrovirally coexpressing $B C R-A B L$ and Alox 15 in Alox $15^{-/-}$BM cells to examine whether restoration of Alox15 expression reverts the defective CML phenotype caused by Alox15 deficiency. We transfected 293T cells and showed that the $B C R-A B L-I R E S-A l o x 15-p M S C V$ construct expressed BCR-ABL and Alox15 (Figure 1F; left panel). We next showed that compared with no CML induction by BCR-ABL in the absence of Alox15, ectopically expressed Alox15 in Alox15 1 - BM cells rescued the defective CML phenotype (Figure 1F; right panel); the development of CML caused by the ectopic expression of Alox 15 with BCR-ABL was consistent with a high percentage of $\mathrm{Gr}-1^{+}$myeloid cells in PB (Supplemental Figure 2A) and infiltration of leukemia cells in the lung and spleen (Supplemental Figure 2B). In contrast, Alox5 did not rescue the defective CML phenotype caused by Alox15 deficiency (Supplemental Figure 2C), indicating that Alox5 and Alox 15 do not mutually compensate in function.

We analyzed $\mathrm{GFP}^{+}$or $\mathrm{GFP}^{-}$cells to reflect the effects of Alox15 deficiency on growth of leukemia $\left(\mathrm{GFP}^{+}\right)$or normal $\left(\mathrm{GFP}^{-}\right)$donor cells in a recipient mouse (Figures 1 and 2). We used alternative approaches to exclude two possibilities after BM transplantation, namely: (a) could recipient cells contribute significantly to the $\mathrm{GFP}^{-}$cell population? and (b) could the $\mathrm{GFP}^{-}$cell population contain leukemia cells that had lost their GFP expression for unknown reasons? To determine the degree of host contribution to cellular compositions in recipient mice after BM transplantation, we transplanted CD45.1 donor BM cells into lethally irradiated CD45.2 recipient mice. Two weeks later, we analyzed BM cells of recipient mice by FACS and found that almost $95 \%$ of total ungated BM cells (Supplemental Figure 3A) and nearly 100\% of HSC-containing LSK ( Lin $\left.^{-} \mathrm{Sca}-1^{+} \mathrm{c}-\mathrm{Kit}^{+} \mathrm{CD} 45.1\right)$ cells (Supplemental Figure 3B) were donor derived (CD45.1-positive). To examine whether $\mathrm{BM}$ reconstitution of recipient mice by donor $\mathrm{BM}$ cells was also true when we induced CML in mice, we transplanted BCR-ABL-transduced CD45.1 donor BM cells ( $\left.\mathrm{GFP}^{+}\right)$into lethally irradiated CD45.2 recipient mice. On day 14 after transplantation, we found that almost all BM cells in the leukemic mice were also donor derived (Supplemental Figure 2C). To confirm that all leukemia cells express GFP in these CML mice, we sorted $\mathrm{GFP}^{+}$ or $\mathrm{GFP}^{-}$leukemia cells from the $\mathrm{PB}$ of $\mathrm{CML}$ mice and assessed BCR-ABL transcripts by RT-PCR. We found that $B C R-A B L$ transcripts were only detected in $\mathrm{GFP}^{+}$, but not $\mathrm{GFP}^{-}$, cells (Supplemental Figure 3D), indicating that leukemia cells did not lose GFP expression in CML mice.

Together, the results described above demonstrate that Alox15 is essential for induction of CML by $B C R-A B L$.

Loss of Alox 15 causes a functional defect in LSCs. The impaired CML development in the absence of Alox15 (Figure 1) could be caused by a decrease in the number of LSCs. Therefore, we tested whether Alox15 regulates the function of LSCs. We compared the numbers of LSCs and normal HSCs (GFP- $\left.\mathrm{Lin}^{-} \mathrm{Sca}-1^{+} \mathrm{c}-\mathrm{Kit}^{+}\right)$in BM of the same CML mice by conducting FACS analyses on days 14 and 20 after CML induction. At both time points, Alox15 deficiency caused a marked reduction of LSCs as compared with LSCs in the BM of WT CML mice (Figure 2A). Loss of Alox15 also caused a reduction of normal BM HSCs (GFP-) but did so to a much lesser degree compared with $\mathrm{GFP}^{+}$LSCs (Figure 2A), suggesting that Alox15 deficiency has a more profound inhibitory effect on LSCs than on normal HSCs. This result was correlated with a more profound effect of Alox15 deficiency on BCR-ABL-expressing common myeloid progenitors (CMPs), granulocyte-macrophage progenitors (GMPs), and megakaryocyte-erythroid progenitors (MEPs) than on the corresponding normal progenitor cells (Figure 2B). Alox15 deficiency did not cause a homing defect in HSCs (Supplemental Figure 4), which could cause a delay in CML development when the cells were transduced by $B C R-A B L$.

To test whether loss of Alox15 causes a decrease in the repopulating ability of LSCs, which could lead to a decrease in the number of BM LSCs (Figure 2A), we transduced WT (CD45.1) or Alox15\% (CD45.2) BM cells with BCR-ABL to induce CML and transplanted equal numbers of WT and Alox15 ${ }^{-/}$BM cells (1:1 mixed) from the CML mice into each lethally irradiated secondary recipient mouse. On day 14 or 20 after transplantation, more than $80 \%$ of $\mathrm{GFP}^{+} \mathrm{Gr}-1^{+}$cells in $\mathrm{PB}$ of the mice were WT $\left(\mathrm{CD} 45.1^{+}\right.$) leukemia cells (Figure 2C), and all these mice eventually died of CML (data not shown). These results showed that loss of Alox15 caused a severe reduction of the repopulating ability of LSCs. Cell cycle analysis of LSCs in the BM of CML mice showed that there was a higher percentage of LSCs in the $\mathrm{S}+\mathrm{G} 2 / \mathrm{M}$ phases in mice receiving $B C R-A B L$-transduced $A l o x 15^{-/-} \mathrm{BM}$ cells than in mice receiving $B C R-A B L$-transduced WT BM cells (Figure $2 \mathrm{D}$ ), presumably due to the compensatory response of Alox $15^{-/-}$LSCs to 
A
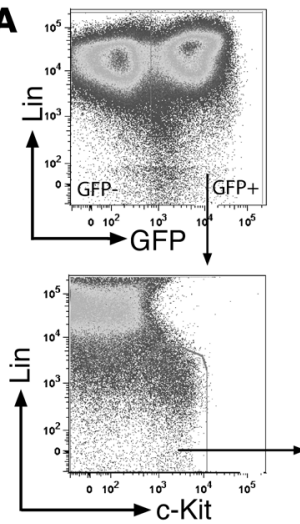

B

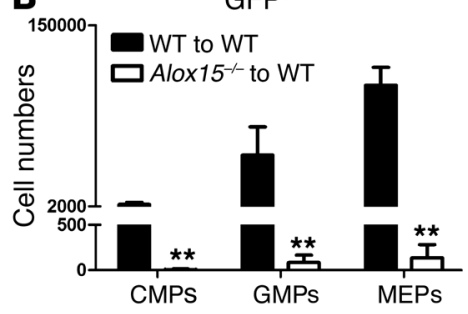

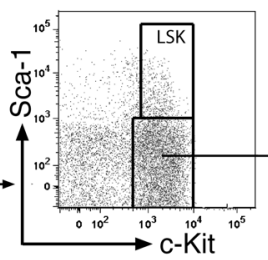

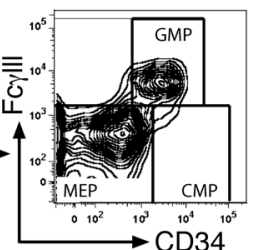

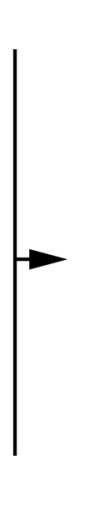

GFP-
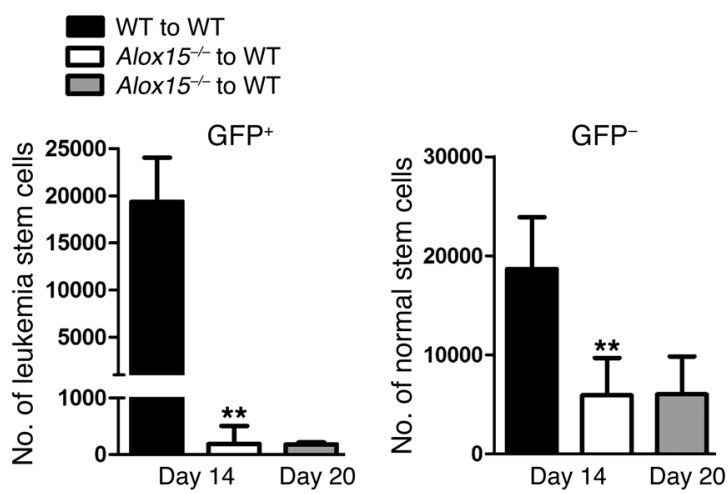

D

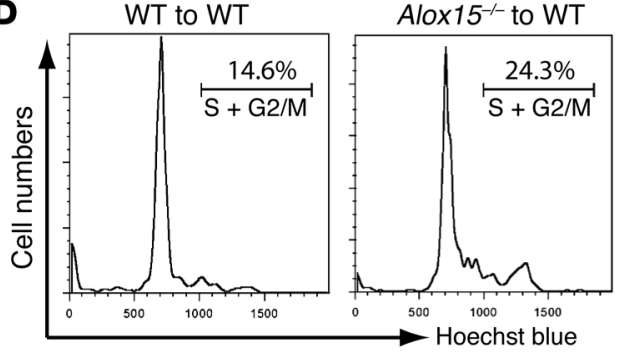

E

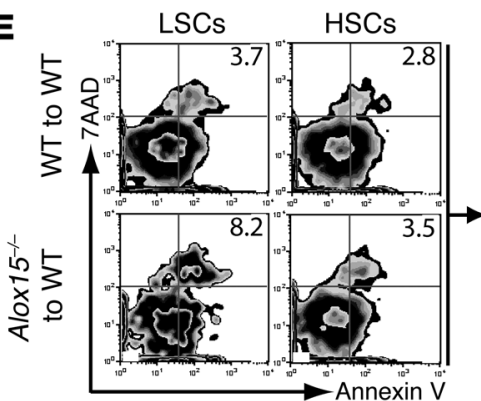

C

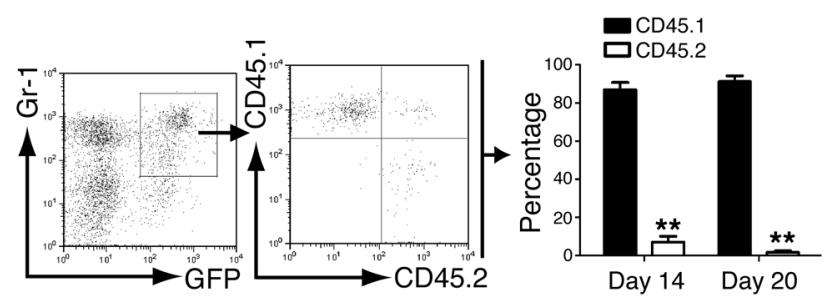

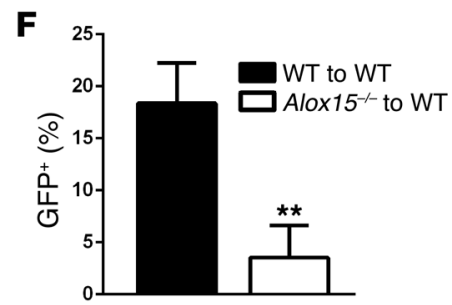

G
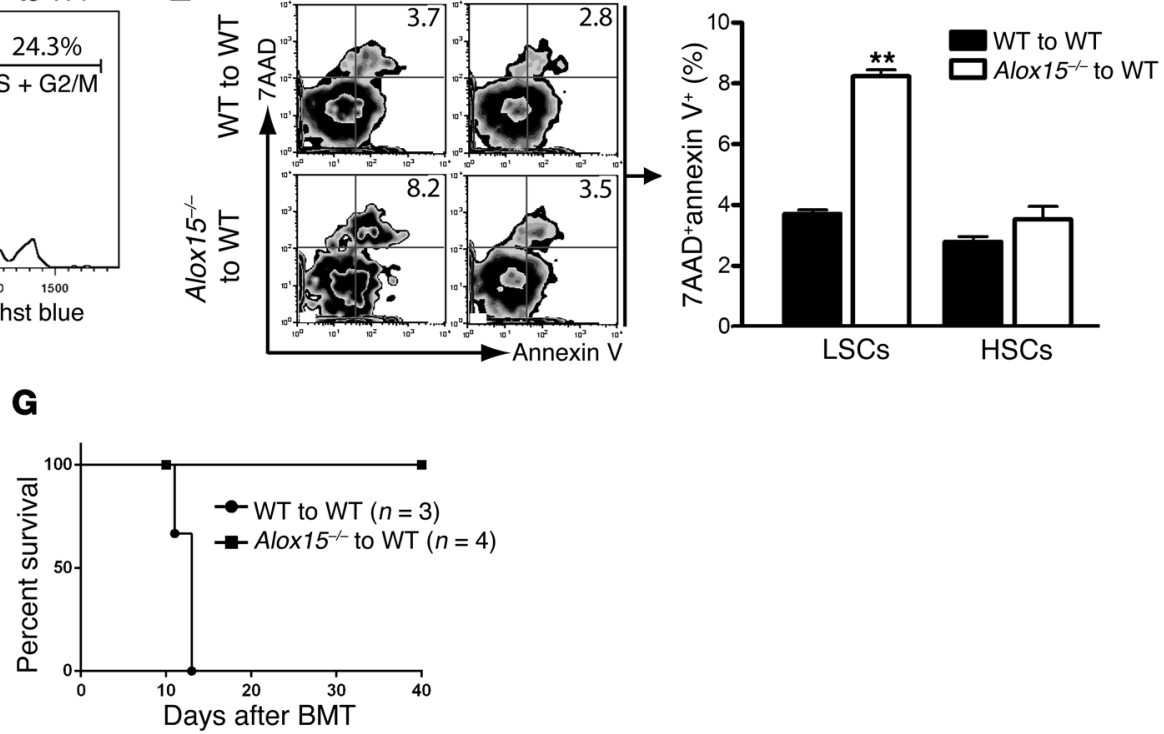

Figure 2. Loss of Alox15 impairs LSC function. (A) FACS analysis showed that loss of Alox15 caused a significant reduction of LSCs in the BM of CML mice $(P<0.05)$ and a smaller reduction of normal HSCs (GFP-Lin $\left.{ }^{-}-K_{i t}{ }^{+} S c a-1^{+}\right)$at days 14 and 20 after CML induction. Results represent the mean \pm SD. (B) Loss of $A$ lox15 caused a more significant reduction of $B C R-A B L$-expressing (GFP+) (left panel) than of non-BCR-ABL-expressing (GFP-) (right panel) CMP, GMP, and MEP cells in the BM of CML mice $(n=4)$. Results represent the mean \pm SD. (C) WT (CD45.1) and Alox15 $5^{-1-}$ (CD45.2) BM cells from CML mice were 1:1 mixed and transplanted into lethally irradiated secondary recipient mice. At days 14 and 20, the percentage of CD45.1 cells was much higher than that of CD45.2+ cells. Results represent the mean \pm SD. (D) Cell cycle analysis showed a higher percentage of LSCs in the $S+G 2 / M$ phase in BM cells of Alox $15^{-1-}$ versus WT CML mice. BM cells were stained with Hoechst blue for FACS analysis. The mean percentage for each cell population $(n=5$ ) is shown. (E) Alox15 deficiency caused increased apoptosis of LSCs over normal HSCs by staining the cells with 7AAD and annexin V. Results represent the mean $\pm \mathrm{SD}$. ( $\mathbf{F}$ and $\mathbf{G})$ Alox15 deficiency impaired the function of BCR-ABL-expressing BM cells in secondary recipient mice receiving $2 \times 10^{6} \mathrm{BCR}$ ABL-transduced WT $(n=3)$ or Alox15-1- $(n=4)$ BM cells per mouse. Alox15 deficiency significantly inhibited BCR-ABL-expressing blood cells (GFP+) (F) and prevented CML development $(\mathbf{C})$. Results represent the mean \pm SD $\left({ }^{* *} P<0.01\right)$.

their reduced stem cell function (Figure 2C). Loss of Alox15 also caused increased apoptosis of LSCs but not of normal HSCs (Figure $2 \mathrm{E}$ ). To further demonstrate the effect of Alox 15 deficiency on LSC function, we induced CML and then transplanted BM cells from CML mice into secondary recipient mice. We found that in the absence of Alox15, BCR-ABL-expressing cells grew at a significantly slower rate (Figure $2 \mathrm{~F}$ ) and had severely defective induction of CML (Figure 2G). Together, these results further indicate 
A

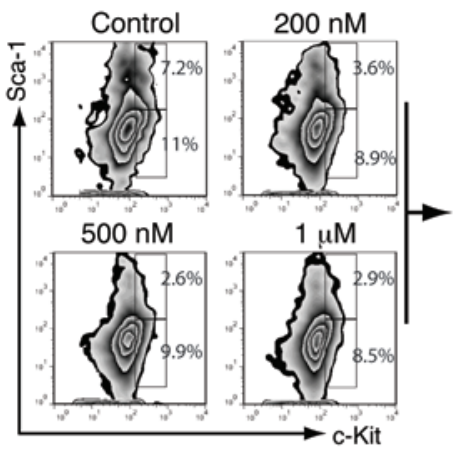

C
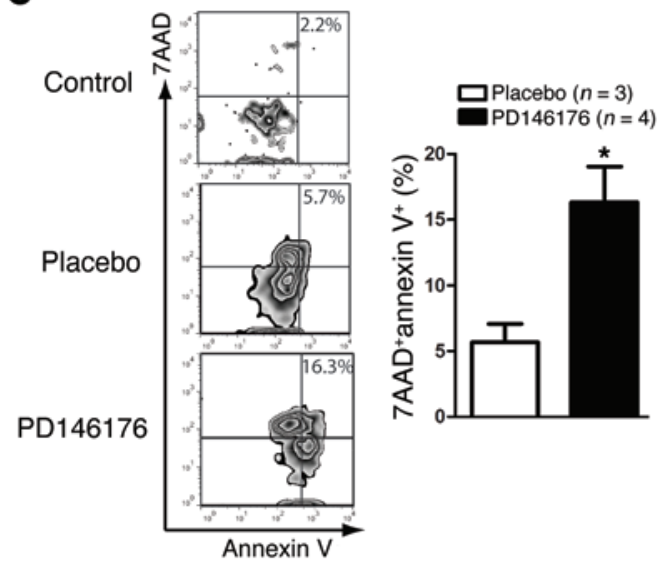

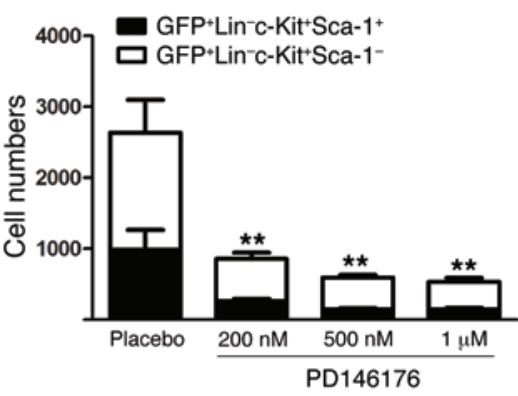

B

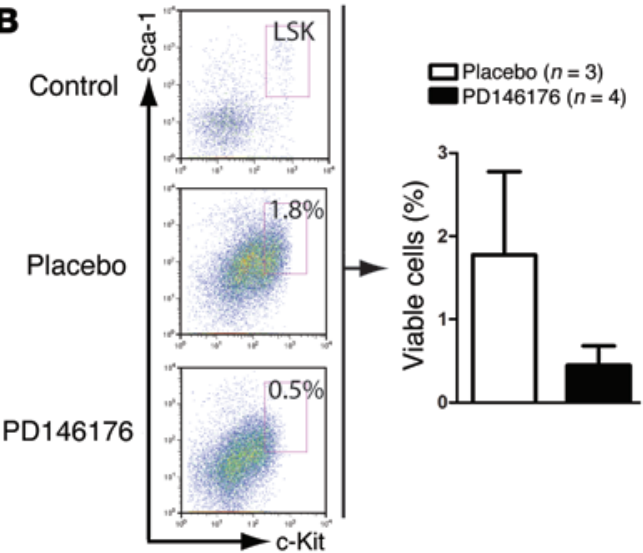

E

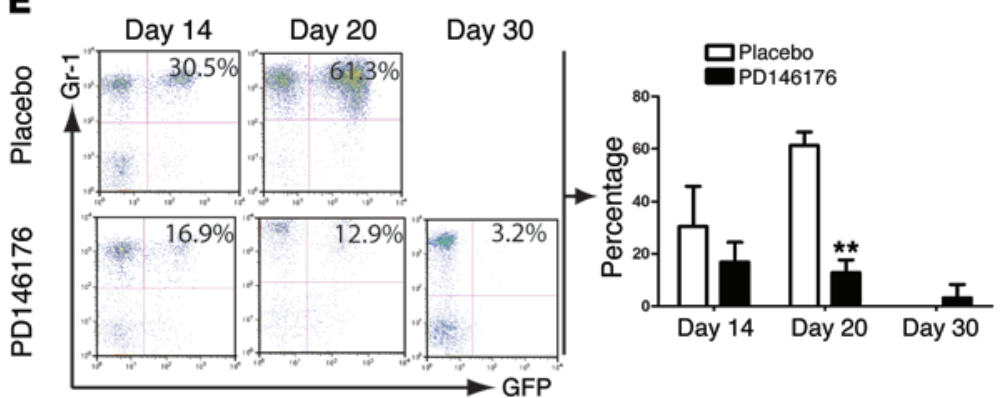

$\mathbf{F}$
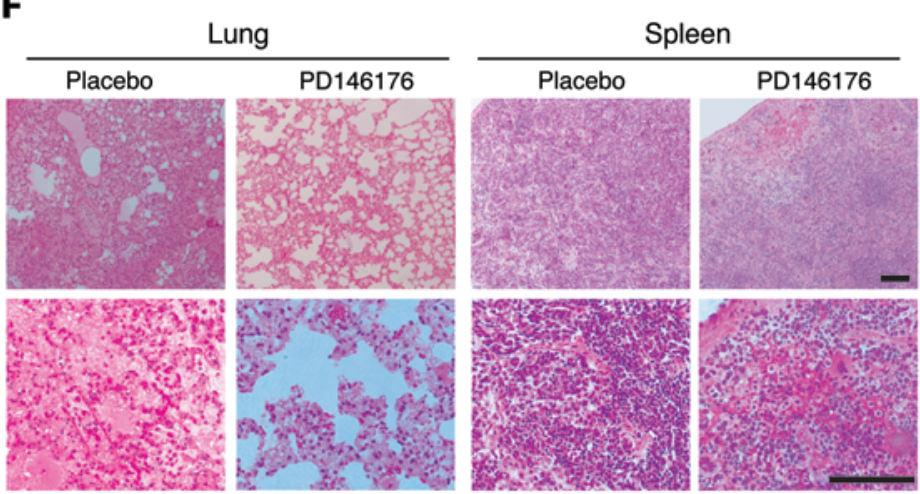

Figure 3. Inhibition of Alox15 impairs LSCs and prolongs survival of CML mice. (A) PD146176 inhibited LSCs in vitro. BM cells from CML mice were cultured $\left(2 \times 10^{6}\right.$ cells per well in a 6-well plate) under stem cell conditions in the presence of DMSO or PD146176 for 3 days, followed by FACS analysis of LSCs and CMPs (GFP+Lin`Sca-1-c-Kit'). Results represent the mean \pm SD. (B) PD146176 inhibited LSC survival in CML mice. CML mice were treated with placebo or PD146176, and at day 14 after CML induction, the percentages of BM LSCs in the treated CML mice were compared. A no-treatment control was used for FACS analysis. (C) PD146176 induced apoptosis of LSCs in CML mice. On day 14 after CML induction, BM cells from placebo- or PD146176-treated CML mice were stained with 7AAD and annexin $\mathrm{V}$, and the percentage of double-positve LSCs was determined by FACS. Results represent the mean \pm SD. (D) Kaplan-Meier survival curves for CML mice treated with placebo or with PD146176 alone. Inhibition of Alox15 by PD146176 significantly prolonged survival of the CML mice ( $n=4$ for each group). (E) In PD146176-treated CML mice, the effectiveness of PD146176 in treating CML mice correlated with a decreased percentage of GFP+ $\mathrm{Gr}^{-1} 1^{+}$leukemia cells in PB. FACS analysis showed the disappearance of $\mathrm{GFP} \mathrm{C}^{+} \mathrm{Cr}-1^{+}$cells in the PB of CML mice treated with PD146176. Results represent the mean \pm SD. (F) Photomicrographs of H\&E-stained lung and spleen sections from CML mice treated with placebo or PD146176. Scale bars: $100 \mu \mathrm{M}$ (top); $50 \mu \mathrm{M}$ (bottom). ${ }^{*} P<0.05 ;{ }^{* *} P<0.01$.

that Alox15 deficiency has a much more profound inhibitory effect on LSCs than on normal HSCs.

Inhibition of 15-LO impairs LSC function and attenuates CML in mice. Deletion of Alox15 caused an impairment of LSC function in CML mice (Figure 2), suggesting that Alox15 is a target gene in LSCs. Therefore, we examined whether inhibition of Alox15 function by the 15-LO inhibitor PD146176 also impairs LSC function. We isolated BM cells from CML mice and cultured the cells in the presence of different concentrations of PD146176 under stem cell culture conditions (34). We observed that PD146176 significantly suppressed LSCs (GFP+LSK) and CMPs (GFP $\left.{ }^{+} \mathrm{Lin}^{-} \mathrm{Sca}-\mathrm{1}^{-} \mathrm{c}-\mathrm{Kit}^{+}\right)$in vitro (Figure 3A). To examine whether PD146176 suppresses LSCs in vivo, the CML mice were treated with a placebo or PD146176, and the percentages of BM LSCs from the treated CML mice were compared between the 2 treatment groups. We found that PD146176 inhibited the proliferation of LSCs (Figure 3B) and 

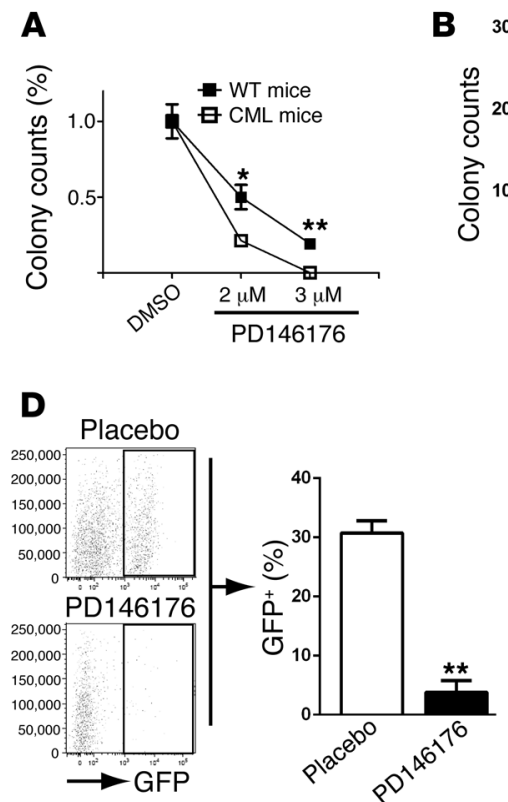

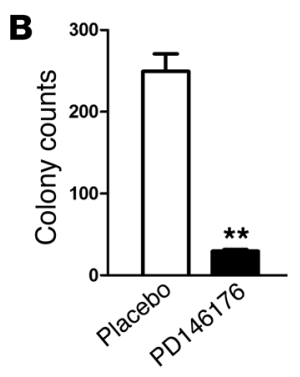

$\mathbf{E}$
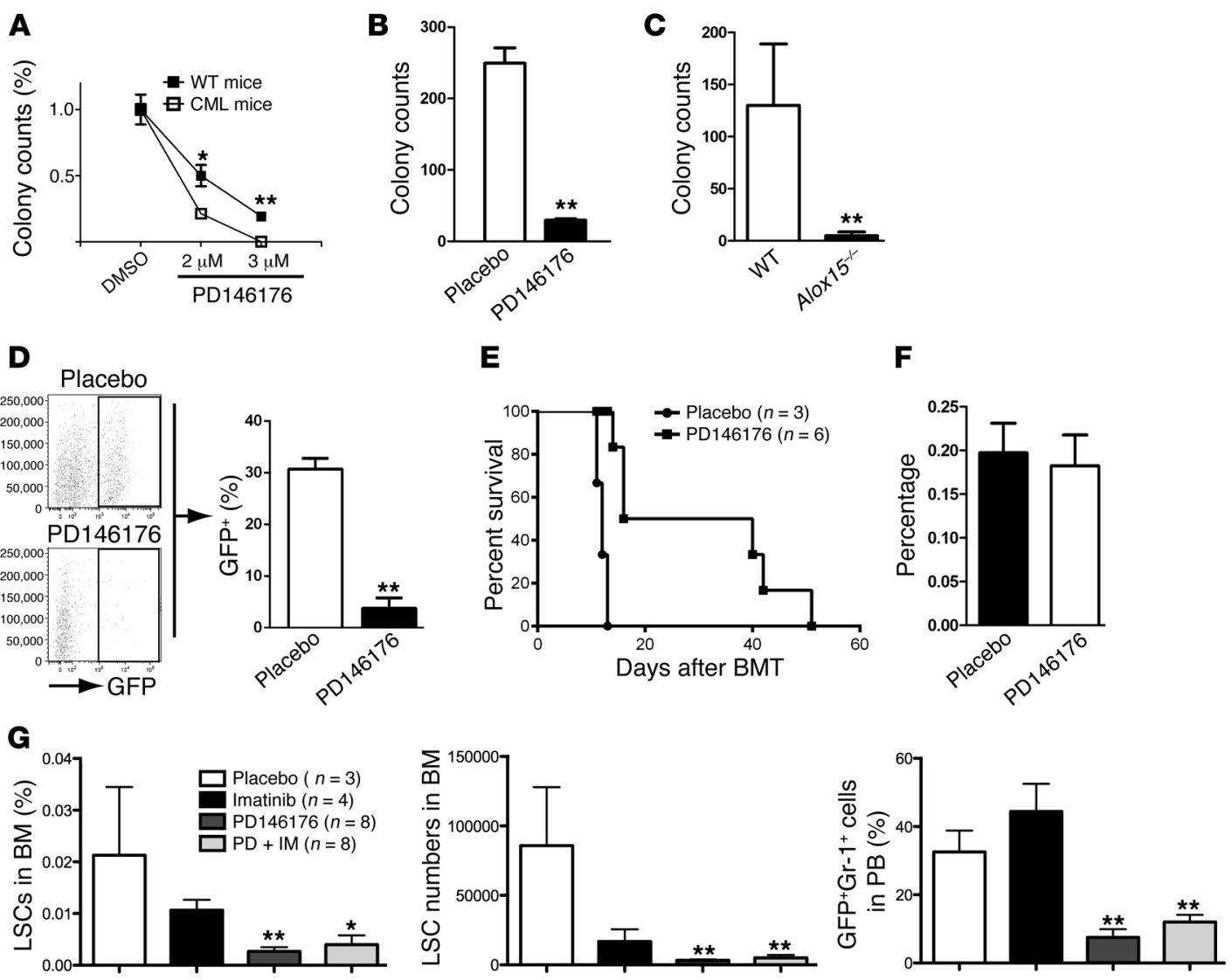

Figure 4. Inhibitory effect of PD146176 on LSCs. (A and B) Quantitation of colony-forming cells (CFCs) was performed after treating CML cells with PD146176 in vitro (A) and in vivo (B). Results represent the mean \pm SEM. For the in vitro assay, BM cells from CML mice on day 14 after CML induction were treated with PD146176 for 48 or 72 hours and plated into stem cell methocult media. Colonies were counted after 7 days. For the in vivo assay, CML mice were treated with PD146176 for 7 days beginning on day 8 after CML induction. BM cells from CML mice were plated, and colonies were counted 7 days later. (C) The colony-forming ability of Alox15 1 - CML BM cells was dramatically decreased compared with that of WT cells. Results represent the mean \pm SEM. (D) PD146176 caused a significant reduction of leukemia cells in the PB of secondary recipient mice. Results represent the mean \pm SD. (E) CML mice were treated with placebo $(n=3)$ or PD146176 $(n=6)$ beginning on day 8 after CML induction, and after a 7-day treatment, BM cells were injected into secondary recipient mice. (F) PD146176 had a weak inhibitory effect on normal HSCs in vivo. CML mice were treated with placebo $(n=4)$ or PD146176 $(n=4)$. The percentage of HSCs in BM was determined by FACS after a 7-day treatment. Results represent the mean \pm SD. (C) CML mice were treated with placebo, PD146176, imatinib, or PD146176 and imatinib (PD + IM) for 7 days, and the percentage of PB leukemia cells or BM LSCs was compared. Results represent the mean $\pm \mathrm{SD} .{ }^{*} P<0.05 ;{ }^{* *} P<0.01$.

also induced apoptosis of LSCs (Figure 3C). Next, we examined whether 15-LO serves as a potential LSC target for the treatment of CML. We found that PD146176 treatment reduced the plasma levels of 15S-hydroxyeicosatetraenoic acid (15S-HETE), a metabolic product of 15-LO, in CML mice (Supplemental Figure 5A), indicating that the metabolic function of Alox 15 was inhibited in CML mice by PD146176. All placebo-treated mice died of CML within 4 weeks after CML induction, whereas almost all PD146176treated CML mice survived (Figure 3D). The effectiveness of PD146176 in treating CML mice correlated with a decreased percentage of $\mathrm{GFP}^{+} \mathrm{Gr}-1^{+}$leukemia cells in $\mathrm{PB}$ (Figure $3 \mathrm{E}$ ) and a much lower degree of leukemia cell infiltration into the lung and spleen (Figure 3F). These drug effects were mostly related to inhibition of Alox15 function, because PD146176 treatment of mice receiving $B C R-A B L$-transduced Alox $15^{-/-}$BM cells did not significantly reduce the percentage of $B C R-A B L$-expressing cells in the $B M$ of the treated mice (Supplemental Figure $5 \mathrm{~B}$ ). In some treated CML mice, $\mathrm{GFP}^{+} \mathrm{Gr}-1^{+}$leukemia cells in both the $\mathrm{PB}$ and $\mathrm{BM}$ dropped to an undetectable level after long-term treatment (Supplemental Figure 5C). To evaluate the impact of PD146176 on normal HSCs in CML mice, we treated CML mice with PD146176 for 90 days. BM cells from PD146176-treated CML mice were analyzed by FACS on day 90 after CML induction. We found that the number of $\mathrm{GFP}^{+} \mathrm{LSK}$ cells was reduced to $0.016 \%$ upon PD146176 treatment, whereas GFP-LSK cell numbers were 10 times higher than those of $\mathrm{GFP}^{+} \mathrm{LSK}$ cells in the treated CML mice, suggesting that targeting of Alox15 has a much less inhibitory effect on HSCs than on LSCs (Supplemental Figure 5D).

Furthermore, we performed a colony formation assay to test the effect of PD146176 on leukemic progenitor cells. PD146176 treatment significantly reduced colony formation both in vitro (Figure $4 \mathrm{~A}$ ) and in vivo (Figure 4B). Consistently, we observed that loss of Alox15 also significantly reduced the colony formation of leukemic progenitor cells (Figure 4C). We also conducted a secondary transplantation assay to further examine the effect of PD146176 on LSC function. We transplanted BM cells from PD146176-treated 

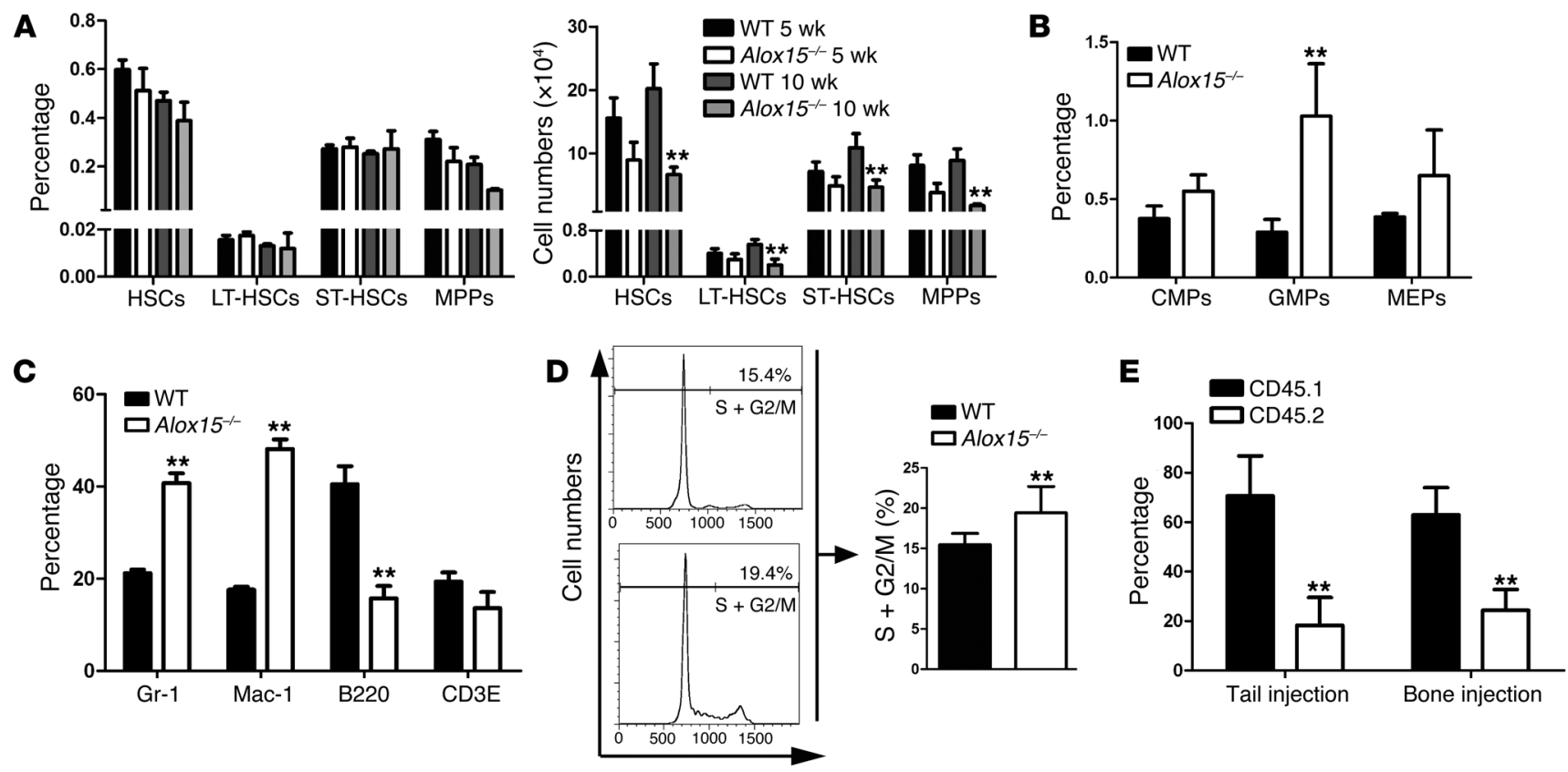

Figure 5. Effect of Alox15 deficiency on the function of normal HSCs in vitro. (A) Alox15 was required for self-renewal of HSCs. BM cells from WT and

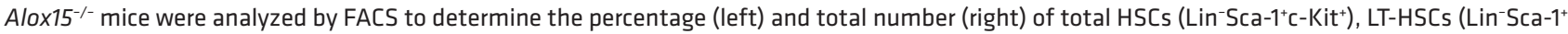

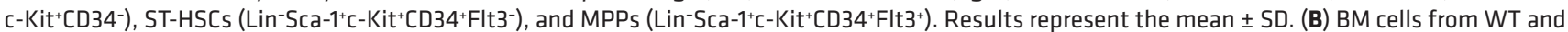
Alox15 1 - mice were analyzed by FACS to determine the percentage of CMPs, GMPs, and MEPs. Results represent the mean \pm SD. (C) Cells from the PB of WT and Alox $15^{-1-}$ mice were analyzed by FACS to determine the percentage of $\mathrm{Gr}-1^{+}, \mathrm{Mac}-1^{+}, \mathrm{B}^{2} 2 \mathrm{O}^{+}$, and $\mathrm{CD} 3 \mathrm{E}^{+}$cells. Results represent the mean $\pm \mathrm{SD}$. (D) Cell cycle analysis showed a higher percentage of HSCs in the S + G2/M phase of the cell cycle in Alox15 ${ }^{-1-}$ mice than in WT mice. BM cells were isolated from WT or Alox15 $1 /$ mice. Cells were stained with Hoechst blue, and DNA content, represented by the percentage of HSCs in the S + G2/M phase of the cell cycle, were examined by FACS. Mean percentage for each cell population $(n=3)$ is shown. Results represent the mean \pm SD. (E) Competitive reconstitution analysis was performed to compare the function of HSCs between Alox15 $5^{--}$and WT mice. Alox15 $5^{--}$(CD45.2) and WT (CD45.1) BM cells were 1:1 mixed and transferred into recipient mice by tail injection or bone injection $(n=5)$. Twelve weeks after BMT, FACS analysis showed the percentage of WT and Alox $15^{-/-}$cells in the BM of recipient mice. Results represent the mean \pm SD. ${ }^{*} P<0.01$.

primary CML mice into secondary recipient mice and found that inhibition of Alox15 caused a significant reduction of leukemia cells in PB (Figure 4D) and delayed CML development in secondary recipient mice (Figure 4E). By contrast, PD146176 had a much weaker effect on normal HSCs (Figure 4F). Next, we tested whether PD146176 affects the homing of CML cells, which could affect treatment efficacy, and found no significant effect (Supplemental Figure 6). Because the BCR-ABL kinase inhibitor imatinib is the standard first-line therapy for CML patients, we tested the combinatorial effect of PD146176 and imatinib on LSCs in CML mice. Compared with imatinib alone, PD146176 alone or in combination with imatinib significantly reduced the percentage and total number of LSCs in both BM and PB (Figure 4G). We found that addition of imatinib did not further increase the inhibitory effect of PD146176, presumably because PD146186 is much more effective than imatinib at inhibiting LSCs. Together, these results indicate that inhibition of Alox 15 function provides a novel therapeutic strategy for suppressing LSCs in CML treatment.

Effect of Alox15 deficiency on normal HSCs. Alox 15 deficiency or inhibition of 15-LO by PD146176 severely impaired the function of LSCs in CML mice (Figures 2 and 3), with a much weaker inhibitory effect on normal HSCs in vitro and in CML mice (Figure 2, A and E). Here, we more directly examined the effect of Alox15 deficiency on normal HSCs by comparing the percentages and function of HSCs in WT and Alox $15^{-/}$mice. A recent study showed that
HSC function requires Alox15 (35). We fully characterized hematopoietic cell lineages in the $\mathrm{BM}$ and $\mathrm{PB}$ of Alox $15^{-/-}$mice in comparison with those of WT mice. The percentages of total HSCs ( $\mathrm{Lin}^{-}$ Sca- $\left.1^{+} \mathrm{c}-\mathrm{Kit}^{+}\right)$, long-term HSCs (LT-HSCs) (Lin-Sca- $\left.1^{+} \mathrm{c}-\mathrm{Kit}^{+} \mathrm{CD} 34^{-}\right)$, short-term HSCs (ST-HSCs) ( Lin $^{-} \mathrm{Sca}-1^{+}{ }^{+}-\mathrm{Kit}^{+} \mathrm{CD} 34^{+} \mathrm{Flt3} 3^{-}$), and multipotent progenitors (MPPs) ( $\left.\mathrm{Lin}^{-} \mathrm{Sca}-1^{+} \mathrm{C}-\mathrm{Kit}^{+} \mathrm{CD} 34^{+} \mathrm{Flt} 3^{+}\right)$

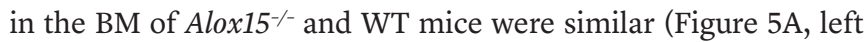
panel), but the total number of these cells was reduced in Alox $15^{-/}$ mice (Figure 5A, right panel). The reduction of the numbers of HSCs in the absence of Alox15 suggests that Alox15 contributes to HSC self-renewal. However, the percentages of BM CMPs, GMPs, and MEPs in Alox15 $5^{--}$mice were not reduced and were significantly higher than those in WT mice (Figure 5B), consistent with higher percentages of $\mathrm{Gr}-1^{+}$and $\mathrm{Mac}-1^{+}$myeloid cells in the $\mathrm{PB}$ of Alox $15^{--}$mice (Figure 5C), although the percentage of $\mathrm{B}$ lymphoid cells $\left(\mathrm{B}_{2} 2 \mathrm{O}^{+}\right)$was significantly lower in the $\mathrm{PB}$ of $\mathrm{Alox} 15^{-/-}$ mice (Figure $5 \mathrm{C}$ ). Furthermore, there were more HSCs in the $\mathrm{S}+\mathrm{G} 2 / \mathrm{M}$ phase of the cell cycle in Alox $15^{-/}$mice than in WT mice (Figure 5D), indicating that there were more proliferating HSCs in Alox15 $1-$ mice, although the numbers of HSCs were significantly lower in these mice (Figure 5A, right panel). This result suggests that the higher cycling property of Alox $15^{-/-}$HSCs is a compensatory response to the reduced number of HSCs in Alox $15^{-/-}$mice, which likely explains the higher percentages of myeloid progenitor and mature myeloid cells in the $\mathrm{BM}$ and $\mathrm{PB}$ of $A l o x 15^{-/}$mice 
A

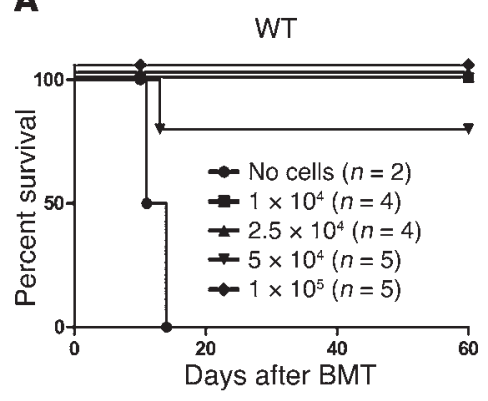

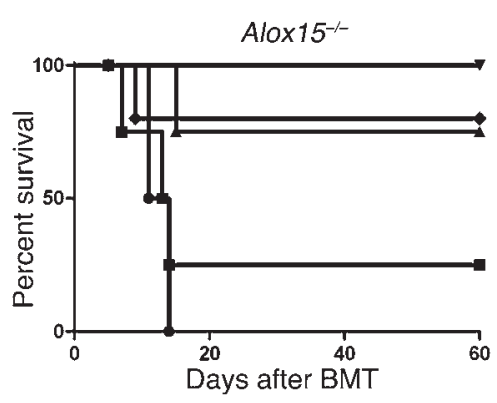

B

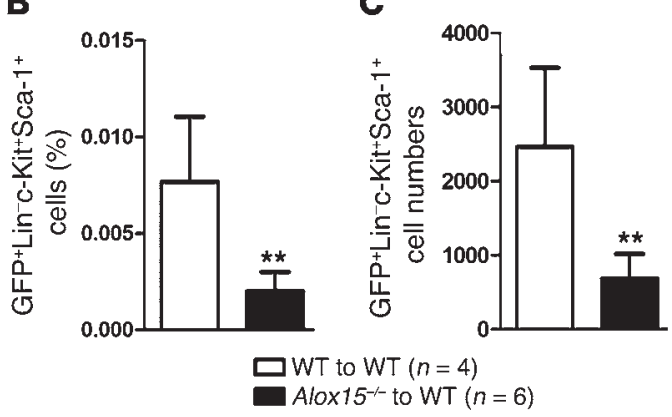

Figure 6. Effect of Alox15 deficiency on the function of normal HSCs in vivo. (A) A BM cell engraftment assay was performed to compare the function

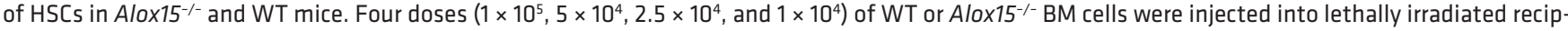
ient mice. Survival curves showed that there was defective BM engraftment in the Alox15/- mice. (B and C) Alox15 ${ }^{-/-}$donor cells exhibited diminished long-term repopulation over controls. Alox $15^{-1-}$ and WT BM cells were transduced with an empty GFP-expressing retrovirus, followed by transplantation into recipient mice. The percentage (B) and total number (C) of GFP+ in $^{-} \mathrm{C}^{-} \mathrm{Kit}^{+} \mathrm{Sca}-\mathbf{1}^{+}$cells were determined 4 months after transplantation. Results represent the mean $\pm \mathrm{SD}$. ${ }^{*} P<0.01$.

(Figure 5, B and C). If this assumption were correct, Alox $15^{-/-}$HSCs would have a lower stem cell function. To test this idea, we compared the function of HSCs in Alox $15^{-/}$and WT mice by conducting a competitive repopulation analysis (Figure $5 \mathrm{E}$ ) and a BM cell engraftment assay (Figure 6A). In the competitive repopulation analysis, equal numbers of WT (CD45.1) and Alox15/- (CD45.2) total BM cells were mixed and injected into the same animal intravenously or directly into the bone. Twelve weeks after the injection, we found that the percentage of CD45.2 cells in the PB was significantly lower than that of CD 45.1 cells (Figure $5 \mathrm{E}$ ), showing a reduced repopulating ability of Alox $15^{-/-} \mathrm{BM}$ cells in recipient mice. In the BM cell engraftment assay, several doses of Alox $15^{-/-}$or WT $\mathrm{BM}$ cells were transplanted into lethally irradiated WT mice. The engraftment ability of Alox $15^{-/}$BM cells was significantly lower than that of WT BM cells, as $1 \times 10^{4}$ or more WT BM cells efficiently protected lethally irradiated recipient mice from death, whereas the high numbers of Alox $15^{-/-}$BM cells only partially rescued the irradiated mice (Figure 6A). We also performed a longterm repopulation assay by transducing $\mathrm{BM}$ cells with MSCV-GFP to label the donor cells and found that the percentage and total number of HSCs $\left(\mathrm{GFP}^{+} \mathrm{Lin}^{-} \mathrm{Sca}-1^{+} \mathrm{c}-\mathrm{Kit}^{+}\right)$in $\mathrm{Alox} 15^{--}$transplants were significantly lower than in WT controls 4 months after transplantation (Figure 6, B and C). These results indicate that Alox $15^{-/-}$ HSCs have some degree of functional defects. However, the effect of Alox15 deficiency on normal HSCs is much less than that on LSCs, as BCR-ABL-expressing Alox $15^{-/-}$LSCs completely lost their ability to induce CML (Figure 1), indicating a therapeutic window for targeting Alox15 in CML treatment.

$P$-selectin (Selp) is a key mediator for the abolishment of CML caused by Alox15 deficiency. To understand the underlying mechanism by which $B C R-A B L$-expressing Alox $15^{-/-}$BM cells fail to induce CML (Figure 1), we compared gene expression profiles between WT and Alox15 $1 /$ HSCs by performing DNA microarray analyses. We intentionally did not compare $B C R-A B L$-expressing WT and Alox $15^{-/}$HSCs, because BCR-ABL-expressing Alox $15^{-1-}$ HSCs have a profound survival defect in vivo (Figure $2 \mathrm{~A}$ ), which makes it difficult to obtain a sufficient number of cells for the analysis. On the other hand, Alox $15^{-/-}$HSCs had a functional defect in rescuing lethally irradiated mice (Figure 6B), which may be medi- ated through the molecular pathway related to the failure of $B C R$ $A B L$-expressing Alox $15^{-/-}$HSCs to induce CML (Figure 1). The DNA microarray analysis showed that in the absence of Alox15, the Selp gene, among others, was upregulated (Figure 7A). We have previously shown that $S e l p$, a cell surface adhesion molecule, plays a suppressive role in CML development $(36,37)$, providing a rationale for studying the functional relationship between Alox15 and Selp in CML. We treated K562 cells with PD146176, and FACS analysis showed upregulated Selp expression on the cell surface (Figure 7B), suggesting that Alox15 suppresses SELP expression. This idea was supported by our finding that treatment of the cells with 15s-HETE and lipoxin A4, the metabolic products of the Alox15 pathway, inhibited the expression of SELP on K562 cells (Figure 7C). These results suggest that Selp is a downstream target gene of Alox15 and mediates the inhibition of LSC function by Alox15 deficiency (Figure 2A). To definitively show the regulation of Selp by Alox15, we crossed Alox $15^{-/-}$mice with Selp $p^{-/-}$mice to generate Alox $15^{-/-} \mathrm{Selp}^{-/-}$homozygous double-knockout mice. If Selp played a critical role in suppressing the function of LSCs in the absence of Alox15, we would expect to see a rescue of the defective CML development caused by Alox 15 deficiency. Indeed, Alox $15^{-/-}$Selp $^{-/-} \mathrm{BM}$ cells transduced with BCR-ABL efficiently induced CML in recipient mice (Figure 7D), whereas Alox $15^{-/-} \mathrm{BM}$ cells transduced with $B C R-A B L$ failed to do so (Figure $1 \mathrm{C}$ and Figure 7D). As compared with the nonrescue control group, the rescue of the defective CML phenotype by the deletion of Selp in Alox $15^{-/-}$BM cells correlated with a higher number of LSCs in BM (Figure 7E) $(P<0.05)$, a higher number of leukemia cells $\left(\mathrm{GFP}^{+} \mathrm{Gr}-1^{+}\right)$in $\mathrm{PB}$ (Figure $\left.7 \mathrm{~F}\right)(P<0.01)$, and severe infiltration of myeloid leukemia cells into the lung and spleen (Figure 7G). A colony-forming assay also showed that Selp deficiency largely rescued the defective CML phenotype by the deletion of Selp in Alox $15^{-/-}$BM cells (Figure 8A). This result was consistent with the significant reduction of Alox $15^{-/-} \mathrm{BM}$ cell apoptosis (Figure $8 \mathrm{~B}$ ). To confirm whether Selp has an effect on normal HSCs, we generated the MSCV-Selp-GFP construct and used MSCV-GFP as a control (Supplemental Figure 7). We transduced BM cells with $M S C V$ Selp-GFP or MSCV-GFP retrovirus and found that the percentages of $\mathrm{GFP}^{+}$cells in $\mathrm{PB}$ (Figure $8 \mathrm{C}$ ) and $\mathrm{Lin}^{-} \mathrm{Sca}-\mathrm{1}^{+} \mathrm{C}-\mathrm{Kit}^{+}$cells in 

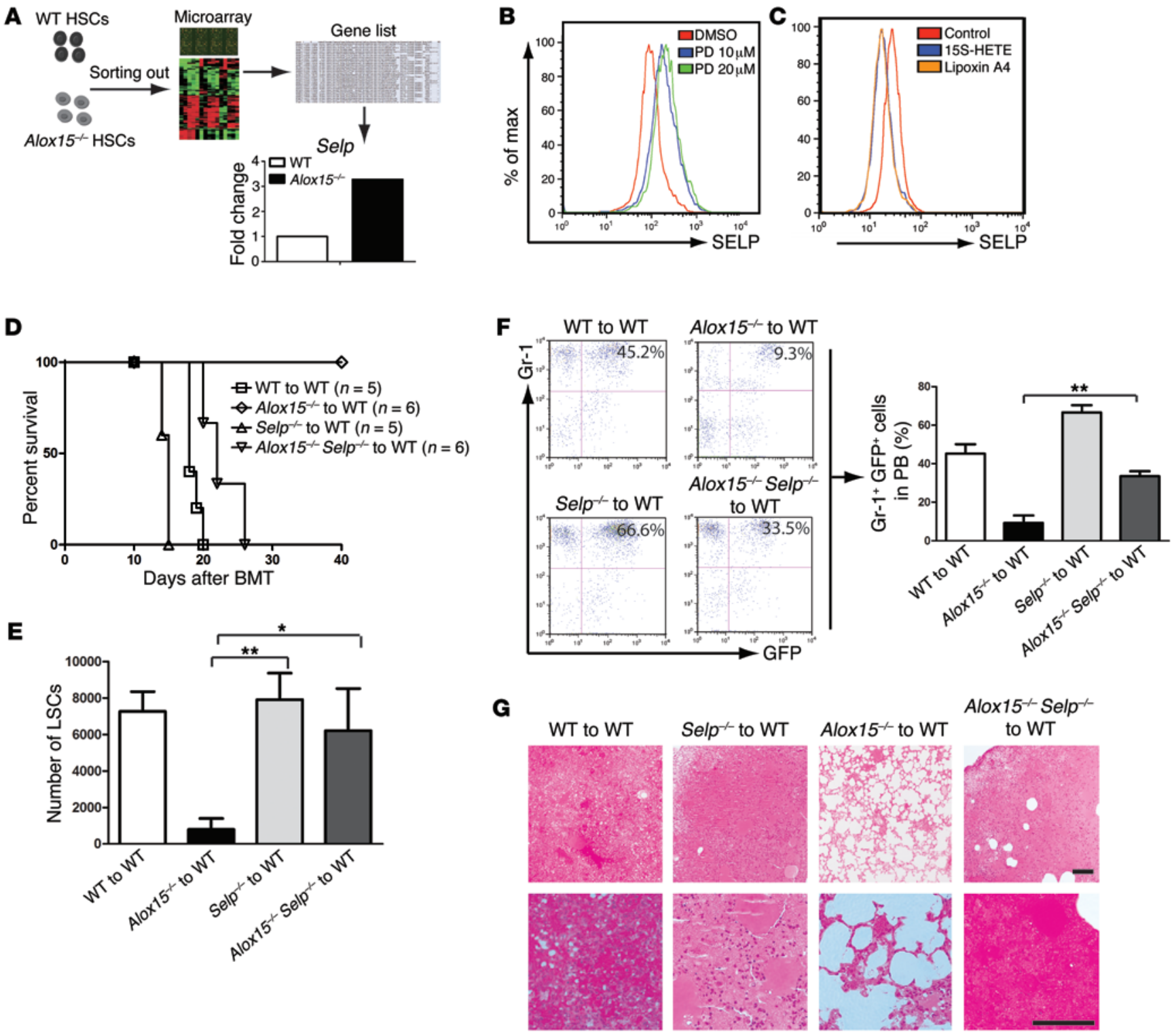

Figure 7. Loss of Alox15 depletes LSCs through its downstream gene Selp. (A) Gene expression profiles of WT and Alox15 1 - HSCs were compared by DNA microarray analysis. In the absence of Alox15, the Selp gene was upregulated. (B) FACS analysis showed that Selp expression on the cell surface was upregulated by treating K562 cells with PD146176. (C) FACS analysis showed that Selp expression on K562 cells was downregulated after treatment with 15S-HETE or lipoxinA4 for 48 hours. (D) Rescue of the defective CML phenotype by the deletion of Selp in Alox15 ${ }^{-/}$BM cells. Alox $15^{-/-}$mice were crossed with Selp ${ }^{-/-}$mice to generate Alox15 $1-$ Selp ${ }^{-/-}$homozygous double-knockout mice. Kaplan-Meier survival curves for recipients of $B C R$ - $A B L-t r a n s d u c e d ~ B M$

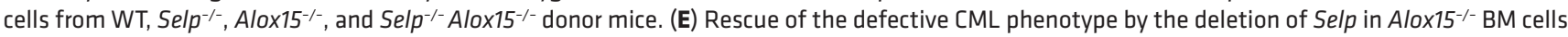
correlated with a high number of LSCs in BM. On day 14 after CML induction, LSCs in recipients of BCR-ABL-transduced BM cells from WT, Selp ${ }^{-/-}$, Alox15 ${ }^{-/-}$, and Selp ${ }^{-1-}$ Alox $15^{-1-}$ donor mice were determined by FACS. Results represent the mean \pm SD. (F) Rescue of the defective CML phenotype by deletion of Selp

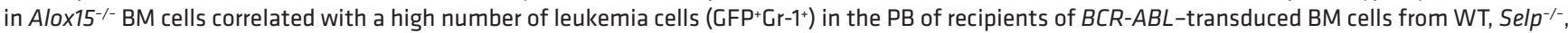
Alox $15^{-1-}$, and Selp ${ }^{-1-}$ Alox $15^{-1-}$ donor mice. Results represent the mean \pm SD. (C) Photomicrographs of H\&E-stained lung sections from recipients of $B C R-$ $A B L$-transduced BM cells from WT, Selp $p^{-1-}$, Alox $15^{-1-}$, and Selp $p^{-1-}$ Alox $15^{-1-}$ donor mice. ${ }^{*} P<0.05 ;{ }^{* *} P<0.01$.

BM (Figure 8D) were much lower in MSCV-Selp-GFP-transduced cells than in GFP-transduced cells at day 120 after transplantation. These results indicate that SELP inhibits HSC function. To understand the underlying mechanism by which SELP regulates the function of HSCs, we compared gene expression profiles in WT and Selp ${ }^{-/-}$HSCs by conducting DNA microarray analysis. We found that loss of Selp led to upregulation and downregulation of a group of genes associated with cell adhesion and apoptosis
(Figure 8E), suggesting that Selp regulates HSC function through altering the movement and survival of HSCs.

Inhibition of Alox15 function suppresses human CML cells. To investigate whether Alox15 is a potential target gene in human CML cells, we treated K562 cells with PD146176 in culture for 48 or 96 hours, respectively, and found that the total cell numbers were greatly reduced (Figure $9 \mathrm{~A}$ ). We also tested the effect of PD146176 on the non- $B C R-A B L$-expressing leukemia cell line 
A
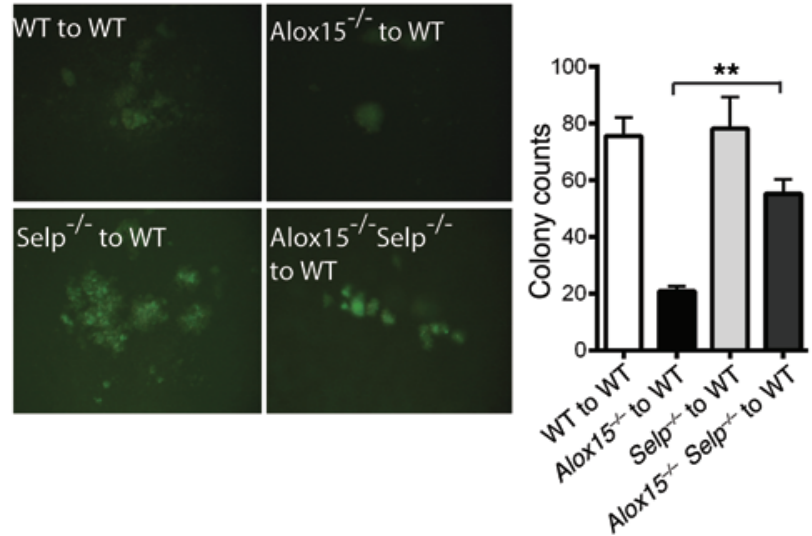

B

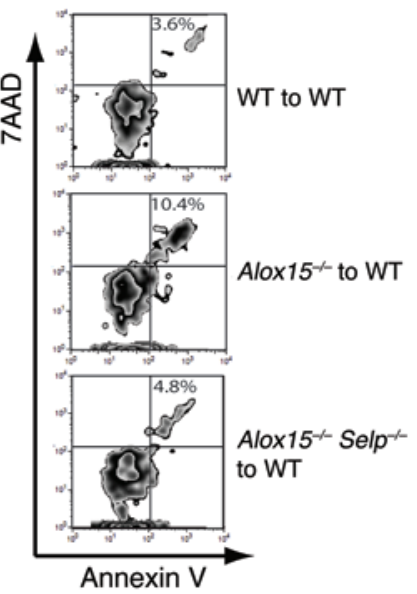

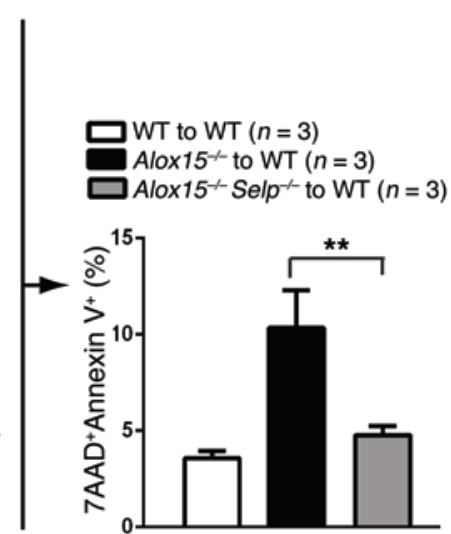

$\mathbf{E}$
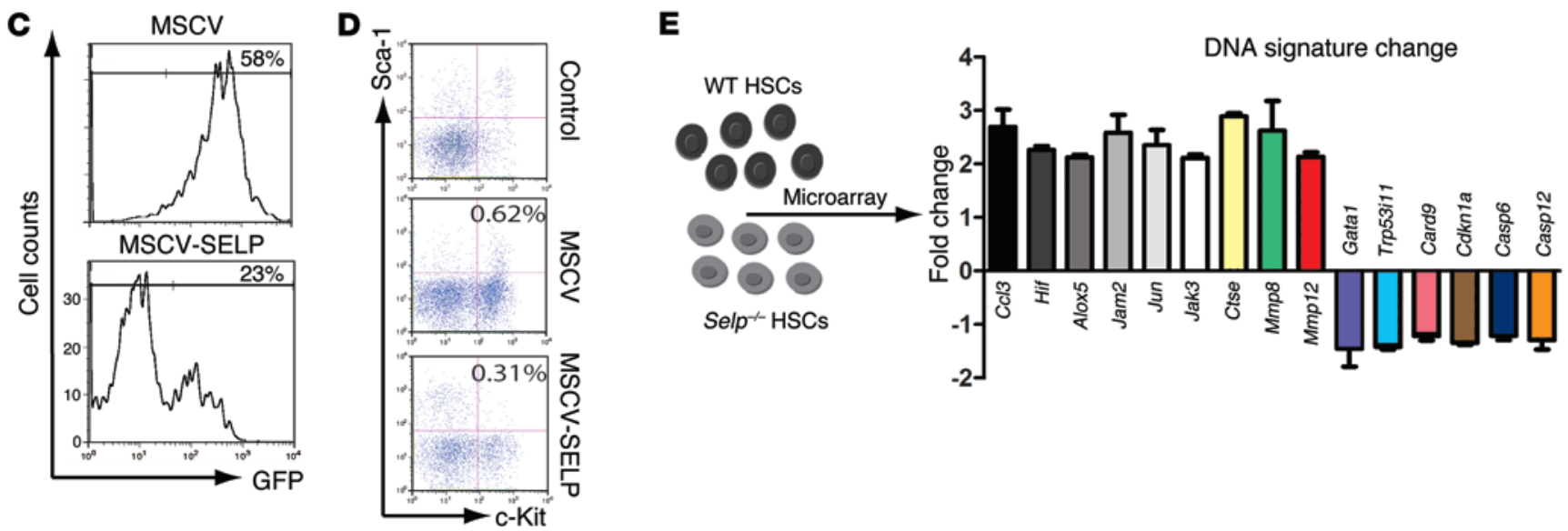

Figure 8. Functional relationship between Alox15 and SELP in HSCs. (A) Colony-forming ability of WT, Alox $15^{-1-}$, Selp $p^{-1-}$, and Alox $15^{-1-}$ Selp $p^{-/-}$CML cells. BM cells were collected from CML mice on day 14 after BM transplantation (BMT) and plated into stem cell methocult media. Colonies were counted after 7 days. Results represent the mean \pm SEM. (B) Apoptotic analysis of BM cells from WT, Alox $15^{-1-}$, and Alox $15^{-/-}$Selp ${ }^{-/-}$mice. Results represent the mean \pm SD. (C and $\mathbf{D})$ Overexpression of Selp inhibits the repopulating ability of HSCs. WT BM cells were transduced with GFP retrovirus or MSCV-Selp retrovirus, followed by transplantation into recipient mice. The percentage of GFP+ blood cells and GFP+Lin-c-Kit ${ }^{+}$Sca- $1^{+}$cells was determined at day 120 after transplantation. A nontransduced control was included to rule out any possible effects of retroviral transduction on the FACS features of the cells. (E) Gene expression profiles of WT and Selp ${ }^{-1-}$ HSCs were compared by DNA microarray assay. A group of cell growth-related genes is shown. Results represent the mean $\pm \mathrm{SD}$. ${ }^{* *} P<0.01$.

HL60. Although PD146176 inhibited the proliferation of HL60 cells, its effect of on HL60 (Supplemental Figure 8) was smaller than on K562 cells (Figure 9A). In addition, PD146176 induced apoptosis of K562 cells (Figure 9B). To determine the signaling pathways involved in the apoptosis of K562 cells, we analyzed protein lysates of K562 cells treated with PD146176 for expression of a group of signaling molecules that have been shown to be involved in the regulation of CSC functions (11, 27, 38-42). We found that PD146176 markedly induced expression of PTEN, ICSBP, and caspase 9 and reduced the expression of $\beta$-catenin, PI3K, and AKT (Figure 9C). PD146176 did not significantly alter the expression of BCL2 or BAX (Figure 9C). To more definitively demonstrate that inhibition of Alox15 function inhibits proliferation of human leukemia cells, we conducted an Alox15 shRNA knockdown experiment using lentivirus. We found that Alox15 knockdown led to growth inhibition (Figure 9D) and apoptosis induction (Figure 9E) of BV-173 cells.

Next, we tested whether inhibition of Alox15 function by PD146176 suppresses human CD34 ${ }^{+}$CML cells. Purified PB CML
CD34 ${ }^{+}$cells (greater than $95 \%$ of the cells were FISH-positive for $B C R-A B \mathrm{~L}$ translocation) were treated in culture with PD146176 alone or in combination with imatinib or nilotinib, followed by analyses of survival, apoptosis, and colony formation of the cells. PD146176 markedly reduced survival (Figure 10A, top panel) and induced apoptosis (Figure 10A, bottom panel) of CML CD34 ${ }^{+}$ cells. PD146176 in combination with imatinib or nilotinib showed a slightly augmented effect as compared with that of single agents in the induction of apoptosis (Figure 10B). The colony-forming assay also revealed that PD146176 significantly inhibited the ability of CML CD34 $4^{+}$cells to form progenitor colonies, with a lesser inhibitory effect on normal human $\mathrm{CD}^{4} 4^{+}$cells (Figure 10C). PD146176 in combination with imatinib or nilotinib did not further inhibit the colony-forming ability of the cells within 24 hours of PD146176 treatment, whereas at 72 hours, PD146176 in combination with nilotinib more significantly inhibited colony formation than did PD146176 alone (Figure 10C). To further test the effect of PD146176 on human CML stem cells, CD34 ${ }^{+} \mathrm{CD} 38^{-}{ }^{-} D 90^{+}$ CML cells were sorted and treated with PD146176. We found that 
A

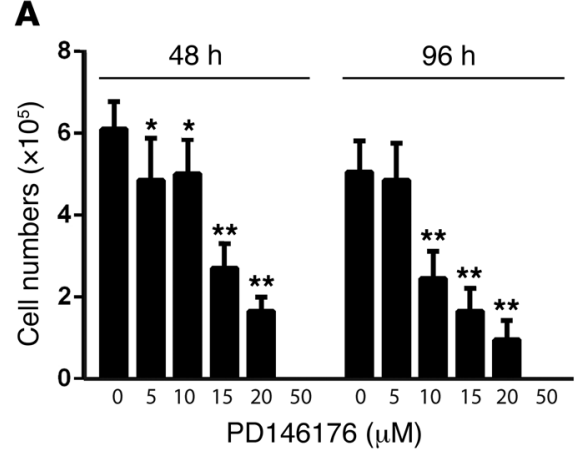

B

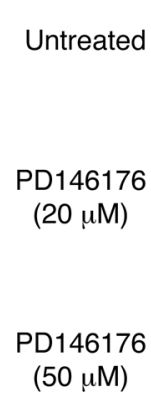

$(50 \mu \mathrm{M})$

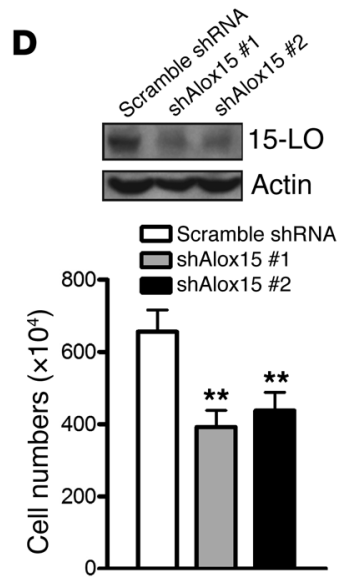

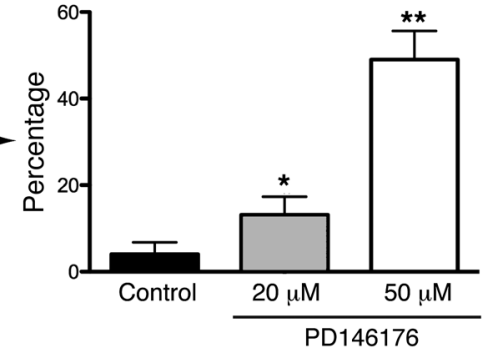

$\mathbf{E}$

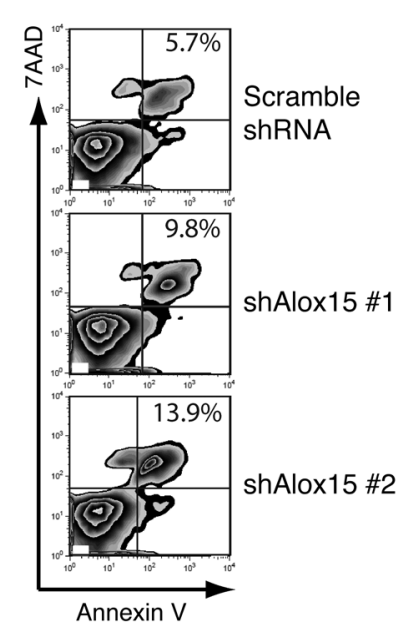

Figure 9. Inhibition of Alox15 function induces apoptosis of human CML cell lines. (A) PD146176 inhibited proliferation of K562 cells. K562 cells were treated with DMSO or PD146176 $(5,10,15,20$, and $50 \mu \mathrm{M})$ for 48 or 96 hours, and live cells were counted. Results represent the mean \pm SD. (B) PD146176 induced apoptosis of $\mathrm{K} 562$ cells. K562 cells were treated with DMSO or PD146176 (20 $\mathrm{M}$ and $50 \mu \mathrm{M})$ for 48 hours. Apoptotic cells (annexin V+7AAD+) were analyzed by FACS. Results represent the mean \pm SD. (C) Signaling pathways affected by PD146176. K562 cells were treated with PD146176 for 48 hours, and protein lysates were analyzed by Western blotting. PD146176 induced expression of PTEN, ICSBP, and caspase 9 and reduced expression of $\beta$-catenin, PI3K, and AKT, but did not significantly alter expression of BCL2 or BAX. (D) Alox15 knockdown caused growth inhibition of leukemia cells. BV-173 cells were transduced with scramble or Alox15-knockdown shRNA (shAlox15), and the transduced cells were selected with puromycin for 48 hours, followed by culturing the cells $\left(2 \times 10^{6}\right.$ cells per well in a 6 -well plate) for 48 hours. At the end of the culture, protein lysates were analyzed by Western blotting for Alox15 expression, and viable cells were counted. Results represent the mean \pm SD. (E) Alox15 knockdown induced apoptosis of leukemia cells. BV-173 cells were transduced with Alox15-knockdown shRNA (shAlox15), and the transduced cells were selected with puromycin for 48 hours, followed by culturing the cells for 48 hours. At the end of the culture, cellular apoptosis was assessed by FACS analysis of annexin $\mathrm{V}^{+} 7 A A D^{+}$cells. ${ }^{*} P<0.05 ;{ }^{* *} P<0.01$.

PD146176 had a significant effect on CML stem cell elimination after 24 hours of drug treatment compared with that observed in the untreated control $(P<0.05)$, whereas nilotinib had very little to no effect on this primitive cell population. The killing effect of PD14176 on CML stem cells was not enhanced by nilotinib (Figure 11A). In the highly stringent in vitro LT culture-initiating cell (LTC-IC) assay, purified CML CD $34^{+} \mathrm{CD} 38^{-} \mathrm{CD} 90^{+}$cells were treated with the drug arms as indicated (Figure 11A) for 24 hours and further used to perform the LTC-IC assay. Treatment with PD146176 resulted in a significant $(P<0.05)$ decrease in CML stem cells in contrast to treatment with nilotinib (Figure 11B) and in increased apoptosis of these cells (Figure 11C). To further confirm the inhibitory effect of PD146176 on the proliferation of human CML stem cells, we labeled CD34 ${ }^{+}$CML cells with CFSE to track cell divisions and treated them with PD146176 $(2 \mu \mathrm{M})$, with or without imatinib $(0.5 \mu \mathrm{M})$ or nilotinib $(0.5 \mu \mathrm{M})$. PD146176 alone or in combination with imatinib or nilotinib dramatically inhibited proliferation, as shown by the fewer number of cell divisions completed in the presence of the drug. Overall recovery of CD $34^{+} \mathrm{CML}$ cells across all cell divisions, including the $\mathrm{CFSE}^{\max }$ undivided cell population, was clearly reduced by PD146176 (Figure 11D). These results demonstrate that Alox15 is a potential target gene for the treatment of human CML.

\section{Discussion}

The essential role of the Alox15 gene in regulating the function of LSCs in CML identifies Alox15 as a novel target gene in LSCs. It is striking that removal of a single gene or inhibition of its function alone causes a depletion of LSCs in CML mice and abolishes CML development. In agreement with our previously proposed hypothesis derived from the study of the specific role of Alox 5 in functional regulation of LSCs (19), our results again support the 
A
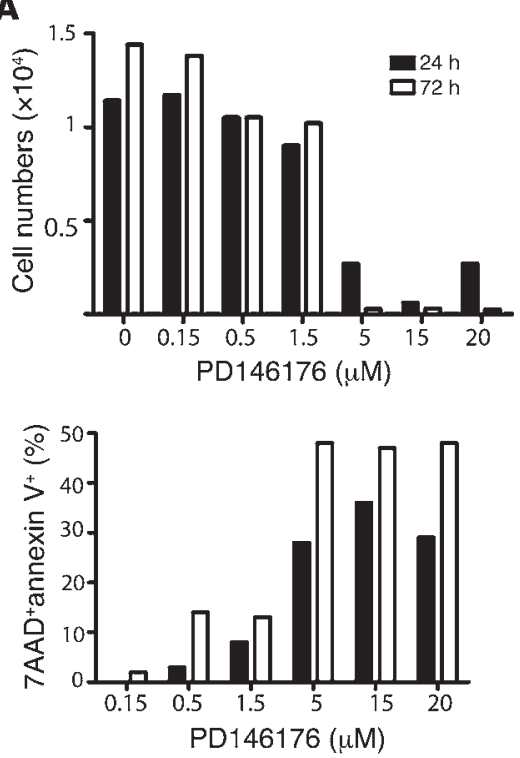

B
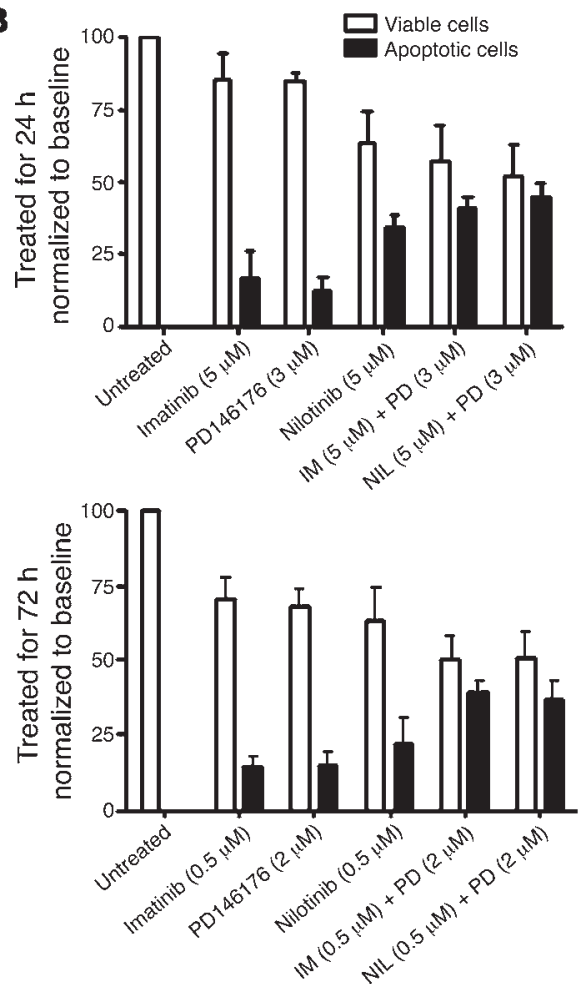

C
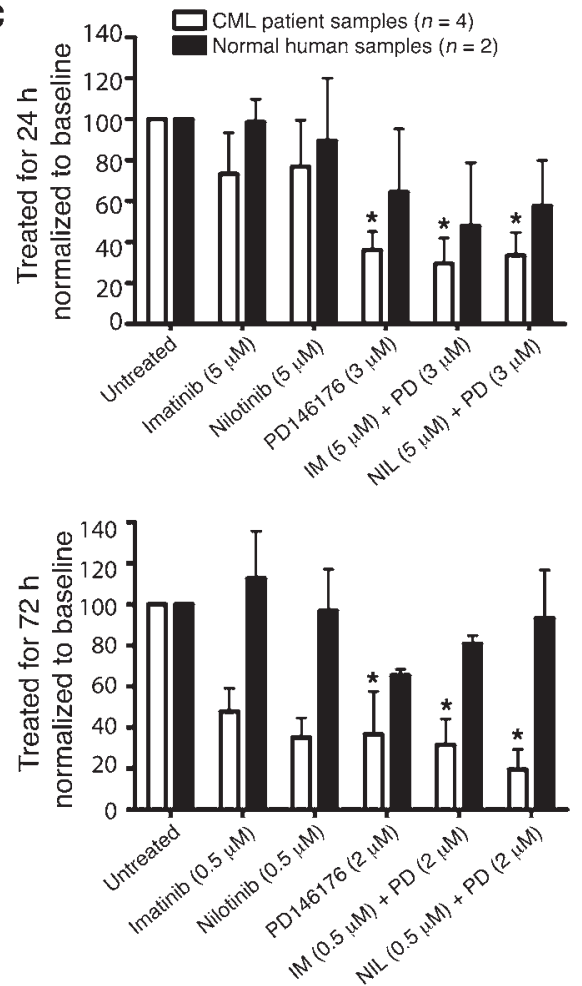

Figure 10. Inhibition of Alox15 function suppresses primary human CML cells. (A) CML CD34+ cells were treated with PD146176 for 24 or 72 hours. Cells were counted using the trypan blue exclusion assay (top), and apoptosis was assessed (annexin $\mathrm{V}^{+} 7 A \mathrm{AD}^{+}$) by FACS (bottom). (B) CML CD34 cells were treated with PD146176, imatinib, or nilotinib alone or in combination for 24 hours (top) or 72 hours (bottom). The percentage of viable and apoptotic (annexin $\mathrm{V}^{+} 7 A A D^{+}$) cells was analyzed. Results represent the mean \pm SEM. (C) CML or normal CD34+ cells were treated with PD146176, imatinib, or nilotinib alone or in combination for 24 hours (top) or 72 hours (bottom) and replated for the CFC assay. Results represent the mean \pm SEM. ${ }^{*} P<0.05$.

principle that targeting CSCs or cancer-initiating cells provides a curative therapeutic strategy for cancer treatment. In stem cell regulation, Alox15 is different from Alox 5 in that it also regulates the function of normal HSCs. However, Alox15 has a much more profound effect on LSCs than on HSCs, providing a therapeutic window for eradicating LSCs through targeting Alox15. Although we observed a strong inhibitory effect of PD146176 on CD34 ${ }^{+}$ human CML cells, future clinical trials will be required to validate whether Alox15 is a useful target gene in CML therapy.

The requirement of Alox 15 for LSC survival and CML development in mice indicates that Alox15 plays a stimulatory role in CML. This conclusion conflicts with a previous study showing that Alox15 plays a suppressive role in a myeloproliferative disorder (MPD) (32). In that study, older Alox15 ${ }^{--}$mice (>12 months of age) were shown to develop an MPD with an increase in $\mathrm{Mac}^{-1}{ }^{+}$cells in $\mathrm{PB}$ and $\mathrm{BM}$, and the mice also developed splenomegaly. In agreement with that study, we show an increase in the percentages of CMPs, GMPs, and MEPs in BM and of Gr-1+ and Mac- $1^{+}$cells in PB. However, we found that the total numbers of HSCs were reduced in Alox $15^{--}$mice, suggesting that Alox15 is required for the survival and self-renewal of HSCs. In addition, there were more HSCs in the $\mathrm{S}+\mathrm{G} 2 / \mathrm{M}$ phase of the cell cycle in Alox $15^{-/-}$mice than in WT mice, showing that there were more proliferating HSCs in Alox $15^{-1-}$ mice, although the total number of HSCs was significantly lower in these mice. Furthermore, we found that the engraftment ability of Alox15 $1-\mathrm{BM}$ cells in lethally irradiated mice was lower than that of WT BM cells. Together, these results suggest that the MPD phenotype in Alox $15^{--}$mice is likely a compensatory response to the reduced number of HSCs in the BM of Alox $15^{-/-}$mice, which is consistent with our observation of more cycling myeloid cells in the spleen and upregulation of BCL2 in Alox $15^{-/-}$mice (32). By contrast, we show that in K562 cells, inhibition of Alox15 function by PD146176 markedly induced expression of PTEN, ICSBP, and caspase 9 and reduced the expression of $\beta$-catenin, PI3K, and AKT, with no significant effects on BCL2 or BAX. We believe that the different interpretations of similar results from the previous study (32) and our current study explain the conflicting role of Alox15.

The mechanism for the functional regulation of LSCs by Alox15 remains largely unknown, and we show that inhibition of Alox15 function by PD146176 alters $\beta$-catenin, PI3K, AKT, PTEN, and ICSBP levels in K562 cells. We and others have recently shown that $\beta$-catenin plays a critical role in CML LSCs $(11,27)$ and that PTEN is a tumor suppressor in LSCs in CML (42). Thus, the regulation of these LSC-related genes by Alox 15 indicates its role in the development of $B C R-A B L$-induced CML. Because Alox 5 also regulates the expression of $\beta$-catenin in LSCs (19), Alox 5 and Alox15 could be functionally linked. However, we observed that Alox $5 \mathrm{did}$ not rescue the defective CML phenotype caused by Alox15 deficiency, suggesting that these 2 genes are independently involved in the regulation of LSCs in CML. As with Alox5, the expression of Alox 15 is upregulated by $B C R-A B L$ and is not altered by imatinib, which may partially explain the insensitivity of LSCs to imatinib in 
A

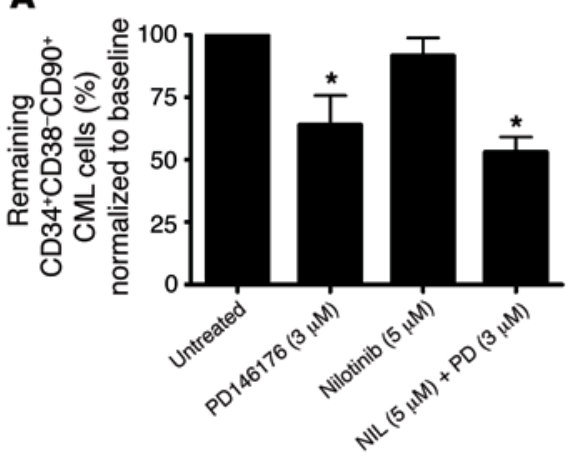

B

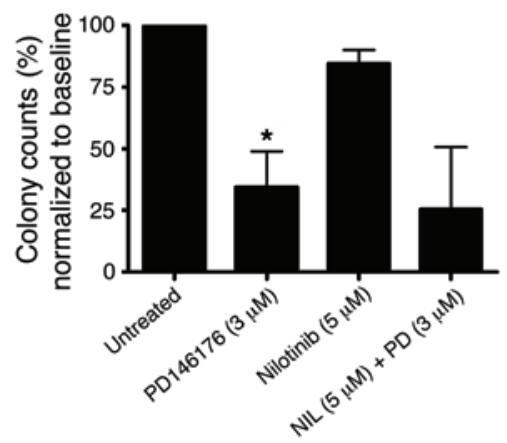

C

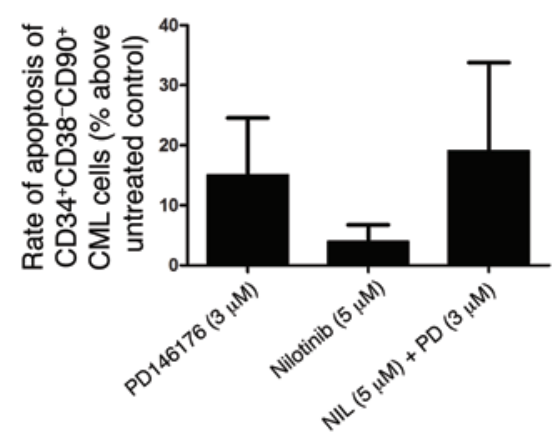

D

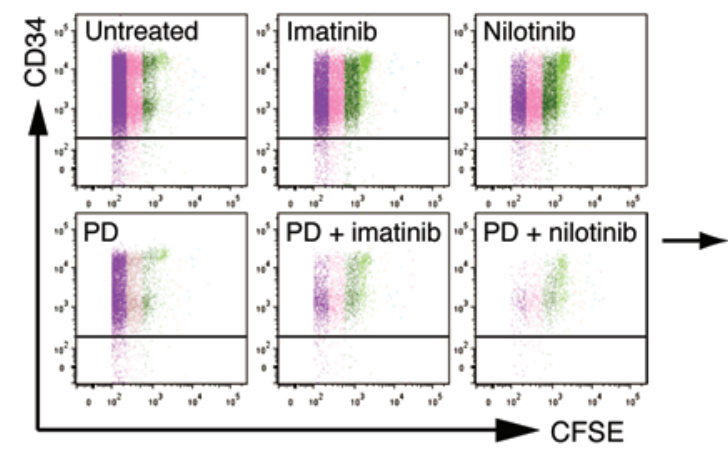

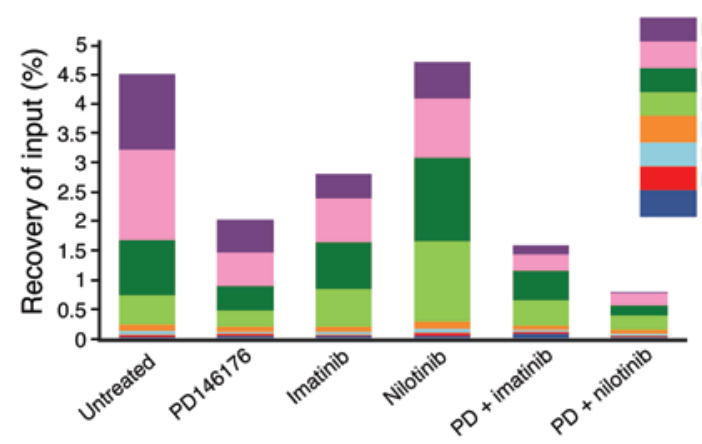

Figure 11. Inhibition of Alox15 function suppresses human CML stem cells. (A) CML stem cells (CD34+CD38-CD90') sorted by FACS were treated with PD146176 or nilotinib or both for 24 hours. The number of treated and untreated CML stem cells was compared. Results represent the mean \pm SEM.

(B) CML stem cells were treated with PD146176 or nilotinib or both for 24 hours and plated on irradiated murine stromal cells for colony formation in the in vitro LTC-IC assay. Results represent the mean \pm SEM. (C) CML stem cells were treated with PD146176 or nilotinib or both for 24 hours. Apoptotic cells (annexin $\mathrm{V}^{+} \mathrm{DAPI}^{+}$) were assessed by FACS. Results represent the mean \pm SEM. (D) CML CD34+ cells from 3 patients were labeled with CFSE and then treated with PD146176 $(2 \mu \mathrm{M})$ with or without imatinib $(0.5 \mu \mathrm{M})$ or nilotinib $(0.5 \mu \mathrm{M})$ for 6 days. The treated $C D 34+C M L$ cells were analyzed by FACS. ${ }^{*} P<0.05$.

CML mice (26). It is reasonable to believe that Alox15 and Alox5 are key members of the molecular pathway critical for LSC function. It is hoped that targeting both Alox 15 and Alox 5 in combination with a $B C R-A B L$ tyrosine kinase inhibitor or a $B C R-A B L$ inhibitor that eliminates $B C R-A B L$ protein, such as a heat shock protein 90 inhibitor (34), would lead to a more complete control of CML. Besides regulating the same signaling molecules, such as $\beta$-catenin and PI3K (43), Alox15 and Alox5 appear to use distinct pathways to function in LSCs. These differences partially explain why both Alox 5 and Alox 15 regulate LSCs but are not functionally linked in signaling. Mechanistically, lipid metabolites produced by Alox15 or Alox 5 could mediate their regulation of LSC function. However, we have observed that expression of $\beta$-catenin, PTEN, and ICSBP is regulated by Alox15 or Alox5 (19), and no published work has indicated that the lipid metabolites produced by Alox 15 or Alox 5 affect the expression of these genes. It is possible that Alox15 and Alox5 regulate LSC function through novel but distinct mechanisms independently of production of their lipid metabolites.

The findings in this study are the first to our knowledge to demonstrate that Alox15 plays an essential role in the functional regulation of LSCs in CML mice and in human CD $34^{+}$CML cells, providing a novel strategy for targeting CML in patients. Human CML microarray studies have shown that Alox15 is differentially expressed in $\mathrm{CD} 4^{+} \mathrm{CML}$ cells (44), suggesting a role of Alox 15 in human CML. In addition, eradication of LSCs in CML mice by inhibiting Alox15 function indicates the importance of the Alox15 pathway in regulating LSC function, and an in-depth study of this Alox15 network is critical to fully understanding the mechanisms for survival and self-renewal of LSCs. Our identification of SELP as a key downstream mediator of Alox15 provides the first clue to further dissecting the Alox15 pathway. Our previous work showed that loss of SELP accelerates $B C R-A B L$-induced CML in mice (36) and that SELP suppresses the functions of HSCs and LSCs (37), suggesting that Selp plays a suppressive role in hematopoiesis and CML development. Furthermore, we showed that SELP expression was upregulated in the absence of Alox15 and that loss of Selp rescued the defective CML phenotype in mice receiving $B C R-A B L$-transduced Alox $15^{-/-}$BM cells, whereas overexpression of Alox15 diminished the function of HSCs. These results support the suppressive role of Selp in the functional regulation of LSCs. The regulatory role of Alox15 in LSCs appears to be cell autonomous, since the recipient mice in our leukemogenesis assay were WT mice. Because Alox15 plays a critical role in regulating LSC function and CML development, a complete understanding of the Alox15 pathway will help in the development of new therapeutic strategies for curing CML. We show that Alox15 function involves several important pathways such as PTEN, PI3K/AKT, and ICSBP, which play critical roles in cancer development. Thus, inhibition of Alox 15 function may be beneficial in the treatment of other types of malignant diseases. 


\section{Methods}

Mice. C57BL/6J-CD45.1, C57BL/6J-CD45.2, and homozygous Alox15knockout (Alox15-/) and homozygous Selp-knockout (Selp $\left.{ }^{-/}\right)$mice on a C57BL/6 background were obtained from The Jackson Laboratory. The Alox $15^{-1-} \mathrm{Selp}^{-1-}$ strain is viable and grows normally and was generated by crossing Alox $15^{-/-}$mice with Selp $p^{-/}$mice. Mice were maintained in a temperature- and humidity-controlled environment and given unrestricted access to a $6 \%$ chow diet and acidified water.

Cell lines. Human BCR-ABL-expressing K562, HL60, and BV-173 leukemia cell lines were grown in RPMI 1640 medium containing $10 \%$ FCS. 293T and NIH3T3 cell lines were grown in DMEM containing $10 \%$ FCS.

FACS and identification of leukemia and normal hematopoietic cell lineages. Hematopoietic cells were collected from the BM and PB of the normal and diseased mice, and red blood cells were lysed with $\mathrm{NH}_{4} \mathrm{Cl}$ red blood cell lysis buffer ( $\mathrm{pH}$ 7.4). The cells were washed with PBS and stained with B220-PE for B cells, Gr-1-APC for neutrophils, Mac-1-PE for macrophages, CD3E-APC for T cells, SELP-PE for Selp, and Sca-1-APC/ c-Kit-PE/CD34-Pacific blue for hematopoietic stem cells. After staining, the cells were washed once with PBS and subjected to FACS analysis.

$B M$ transduction and transplantation. The retroviral vector MSCVIRES-GFP carrying $p 210 B C R-A B L \mathrm{cDNA}$ was used to make high-titer, helper-free, replication-defective ecotropic virus stock by transient transfection of $293 \mathrm{~T}$ cells using the kat system as previously described (45). The viral titers were evaluated by infecting 3T3 cells and analyzing protein lysates by Western blotting for detection of BCR-ABL protein expression levels. The viruses were normalized to a similar titer prior to induction of CML in mice. Six- to 8-week-old WT C57BL/6, Alox $15^{-/}$, or Selp ${ }^{-/-}$mice were used for leukemogenesis experiments. Induction of CML was performed as previously described $(34,46)$. Briefly, to model CML, BM from 5-FU-treated $(200 \mathrm{mg} / \mathrm{kg})$ donor mice was transduced twice with $B C R-A B L$ retrovirus by cosedimentation in the presence of IL-3, IL-6, and stem cell factor (SCF). WT recipient mice received $1,100 \mathrm{cGy}$ gamma irradiation (given by 2 split 550 -cGy doses), and $0.5 \times 10^{6}(\mathrm{CML})$ cells were transplanted into the recipient mice via tail vein injection. Each recipient mouse received $5 \times 10^{5}$ BCR-ABL-transduced donor BM cells from WT, Alox $15^{-/}$, or Selp ${ }^{-1-}$ mice. There were typically 10 mice in each cohort of CML mice; however, occasionally, a few mice died prematurely within 10 days after CML induction due to technical reasons. When this occurred, the dead mice were removed from the experiment.

Western blot analysis and antibodies. Antibodies against c-ABL, $\beta$-catenin, BCL-2, BAX, ICSBP, $\beta$-actin, and Alox15 were purchased from Santa Cruz Biotechnology Inc., and antibodies against P53, PTEN PI3K, AKT, and caspase 9 were purchased from Cell Signaling Technology. Protein lysates were prepared by lysing cells in RIPA buffer, and Western blot analysis was performed as previously described (47).

Real-time PCR. Total mRNA was extracted from LSCs isolated by FACS sorting. cDNA was synthesized using the Ovation-Pico (NuGEN) cDNA synthesis method. RT-PCR was performed to detect Alox15 expression with the following primers: forward primer, CAGGGATCGGAGTACACGTT; reverse primer, GATTGTGCCATCCTTCCAGT. The Power SYBR Green PCR master mix was obtained from Applied Biosystems. The number of copies of Alox 15 mRNA relative to 1,000 copies of $\beta$-actin mRNA reflect the abundance of mRNA copies detected.

In vitro culture of LSCs. BM cells isolated from CML mice were cultured in vitro in the presence of StemSpan SFEM (STEMCELL Tech- nologies), SCF, insulin-like growth factor-2, thrombopoietin, heparin, and $\alpha$-fibroblast growth factor as described previously (34).

Homing experiment. The ability of WT and Alox15-deficient BM cells to home the bones of recipients was compared. A GFP strain was used as a WT control mouse, in which all blood cell lineages express GFP. GFP and Alox $15^{-/-}$mice are positive for CD 45.2. BM cells from the GFP and Alox $15^{-/-}$mice were 1:1 mixed and then injected into CD45.1 mice. The percentages of $\mathrm{CD} 45.2^{+} \mathrm{GFP}^{+}$(WT) and CD45.2 $\mathrm{GFP}^{-}$(Alox15deficient) cells in the PB of CD45.1 recipient mice were compared.

DNA microarray. BM cells from WT, Alox $15^{-/}$, or Selp $p^{-/}$mice were isolated and subsequently FACS sorted for HSCs $\left(\mathrm{Lin}^{-} \mathrm{c}-\mathrm{Kit}^{+} \mathrm{Sca}-1^{+}\right.$). Total RNA was isolated from HSCs, and DNA microarray analysis was further carried out using Affymetrix chips. The DNA microarray results were deposited in the Gene Expression Omnibus database (GEO GSE29348 and GSE57459).

Lentiviral shRNA knockdown of Alox15 expression. BV-173 cells $\left(3 \times 10^{6}\right)$ were mixed with $0.5 \mathrm{ml}$ Alox15 shRNA lentivirus in 6-well plates and spun at $1,900 \mathrm{~g}$ for 1.5 hours at $37^{\circ} \mathrm{C}$ in the presence of polybrene $(10 \mu \mathrm{g} / \mathrm{ml})$. The medium was changed after 24 hours, and puromycin $(2.5 \mu \mathrm{g} / \mathrm{ml})$ was added for selection of the transduced cells.

Histology. The lungs from the placebo- or drug-treated mice were fixed in Bouin fixative (Fisher Scientific) for 24 hours at room temperature, followed by an overnight rinse in water. Sections $(10-\mu \mathrm{m})$ were stained with H\&E and observed using a model DMRE compound microscope (Leica). All sections were imaged with a $2.5 \times \mathrm{PH} 1$ objective (NPLan, NA 0.25 ) and $\times 10$ PH1 objective (NPLan, NA 0.40). All images were imported into MetaMorph software (Molecular Devices) as a series of tagged image files and then constructed in Adobe Photoshop CS4 (Adobe).

Patient samples. The $\mathrm{CD}_{3} 4^{+}$cell population was enriched using ClinimACS (Miltenyi Biotec) according to standard protocols, before storage in aliquots at $-150^{\circ} \mathrm{C}$. CML CD $34^{+}$samples $(n=4)$ were cultured in a humidified incubator at $37^{\circ} \mathrm{C}$ and $5 \% \mathrm{CO}_{2}$ in serum-free medium (SFM) consisting of Iscove's modified Dulbecco's medium (SigmaAldrich) supplemented with serum substitute (BSA, insulin, and transferrin [BIT9500]; STEMCELL Technologies), $2 \mathrm{mM}$ L-glutamine, $10^{5}$ units $/ \mathrm{ml}$ penicillin, $100 \mathrm{mg} / \mathrm{ml}$ streptomycin, $0.1 \mathrm{mM}$ 2-mercaptoethanol, and $0.8 \mu \mathrm{g} / \mathrm{ml}$ LDL (all from Sigma-Aldrich). SFM was supplemented with a growth factor cocktail of $0.20 \mathrm{ng} / \mathrm{ml}$ recombinant human (rh) SCF, $1 \mathrm{ng} / \mathrm{ml} \mathrm{rh}$ IL-6, $0.20 \mathrm{ng} / \mathrm{ml} \mathrm{rh}$ granulocytemacrophage CSF (GM-CSF) (Chugai Pharma Europe), $0.05 \mathrm{ng} / \mathrm{ml} \mathrm{LIF}$, $0.2 \mathrm{ng} / \mathrm{ml} \mathrm{MIP \alpha}$ (all from STEMCELL Technologies unless otherwise indicated). "Normal CD34" or non-CML samples $(n=2)$ were $\mathrm{CD} 34^{+}$-enriched leukapheresis products maintained and used as described for CML CD34 ${ }^{+}$samples.

Cell counting and apoptosis assays. After retrieval from $-150^{\circ} \mathrm{C}$ aliquots and an overnight incubation, cells were seeded in 24-well plates at $1 \times 10^{6}$ cells $/ \mathrm{ml}$ before drug exposure. After treatment, the aliquots were removed and counted in duplicate by trypan blue (Sigma-Aldrich) exclusion. Apoptosis was quantified by phosphatidylserine externalization. Briefly, samples were stained with annexin V-FITC and 7AAD (Via-Probe solution; both from BD Biosciences) according to the manufacturer's recommendations. FACSCalibur flow cytometry (BD Biosciences) enabled the distinction of viable cells (annexin V-FITC' ${ }^{-}$7AAD') from those in apoptosis (annexin V-FITC ${ }^{+}, 7 \mathrm{AAD}^{+}$). Unless otherwise indicated, all results are expressed as the mean \pm SEM.

Mouse colony forming cell assay. To evaluate the effect of PD146176 on CML progenitor cells, BCR-ABL-expressing cells from the BM of 
CML mice were treated with PD146176 in vitro in a colony-forming assay; also, CML mice were treated with PD146176, and then BM cells were isolated for analysis in the colony-forming assay, which was carried out as previously described (48).

Human colony-forming cell assay. Primary CML cells or non-CML $\mathrm{CD}^{+} 4^{+}$cells were treated for 24 or 72 hours with the indicated concentrations of PD146176, imatinib, or nilotinib, individually or in combination (Figure 10). Untreated and drug-treated cells and cells that had no prior culture or treatment (baseline) were seeded in methylcellulose medium (Methocult H4034; STEMCELL Technologies). The formation of colonies was assessed 14 days after plating 2,500 cells per plate.

Human CML stem cell assay. After purifying a primitive population of LSCs $\left(\mathrm{CD} 34^{+} \mathrm{CD} 38^{-}\right.$and $\left.\mathrm{CD}^{\circ} 0^{+}\right)$using sorting techniques, the CML cells were treated with PD146176, nilotinib, or both. LSCs were identified and quantitated by FACS. In the highly stringent in vitro LTC-IC assay, purified CML cells that expressed CD34 ${ }^{+} \mathrm{CD} 38^{-}$and $\mathrm{CD}^{+} 0^{+}$only were treated with the drug arms, as indicated (Figure 11), for 24 hours and were plated on irradiated murine stromal cells. After 6 weeks, cells were harvested, counted, and inoculated into methylcellulose media (Methocult H4435; STEMCELL Technologies). After 2 weeks, colonies were counted, and a functional readout was obtained for quantitation of the most primitive cells.

Drug treatment. To model CML, BM from 5-FU-treated (200 $\mathrm{mg} / \mathrm{kg}$ ) donor mice was transduced twice with $B C R-A B L$ retrovirus by cosedimentation in the presence of IL-3, IL-6, and SCF. WT recipient mice received 1,100 cGy gamma irradiation (administered by 2 split 550-cGy doses), and $0.5 \times 10^{6}(\mathrm{CML})$ cells were transplanted into recipient mice via tail vein injection. After 8 days, CML mice with confirmed disease were randomly enrolled into the placebo or drug treatment groups. PD146176 (Cayman Chemical) was dissolved in DMSO, cremophor EL, alcohol, and PBS. The drug was administered orally in a volume of less than $0.3 \mathrm{ml}$ by gavage $(100 \mathrm{mg} / \mathrm{kg}$ every day for PD146176) beginning 8 days after BM transplantation and continuing until the morbidity or death of the leukemic mice. The placebo consisted of a solution containing DMSO, cremophor EL, alcohol, and PBS.
Statistics. Statistical analyses were performed using a 1-tailed Student's $t$ test $\left({ }^{*} P<0.05 ;{ }^{* *} P<0.01\right)$ and GraphPad Prism software, version 5.01 for Windows (GraphPad Software). A $P$ value less than 0.05 was considered statistically significant.

Study approval. Mice were maintained and handled in accordance with the protocols and regulations approved by the IACUC of the University of Massachusetts Medical School. Patient samples consisted of leukapheresis products taken at the time of diagnosis of chronic-phase CML, and written informed consent was obtained in accordance with Declaration of Helsinki principles and with IRB approval from the National Health Service Greater Glasgow.

\section{Acknowledgments}

This work was supported by grants from the Leukemia \& Lymphoma Society and the NIH (R01-CA122142, R01-CA114199) to S. Li and from the Leukaemia \& Lymphoma Research UK (LLR 08071, 13035) and Cancer Research UK (C11074/A11008) to S.A. Abraham and T.L. Holyoake. Sorting of human stem cells was supported by a Kay Kendall Leukaemia Fund grant (KKL501), and access to Biobank samples was supported by the Glasgow Experimental Cancer Medicine Centre (ECMC), which is funded by Cancer Research UK and by the Chief Scientist's Office (Edinburgh, United Kingdom).

Address correspondence to Shaoguang Li, University of Massachusetts Medical School, 364 Plantation Street, Worcester, Massachusetts 01605, USA. Phone: 508.856.1691; E-mail: Shaoguang. Li@umassmed.edu.

Yaoyu Chen's present address is: Department of Oncology, Novartis Institutes for BioMedical Research, Cambridge, Massachusetts, USA.

Cong Peng's present address is: Department of Hematology/ Oncology, Children's Hospital Boston, Harvard Medical School, Boston, Massachusetts, USA.
1. Al-Hajj M, Wicha MS, Benito-Hernandez A, Morrison SJ, Clarke MF. Prospective identification of tumorigenic breast cancer cells. Proc Natl Acad Sci U S A. 2003;100(7):3983-3988.

2. Jordan CT, Guzman ML, Noble M. Cancer stem cells. N Engl J Med. 2006;355(12):1253-1261.

3. Pardal R, Clarke MF, Morrison SJ. Applying the principles of stem-cell biology to cancer. Nat Rev Cancer. 2003;3(12):895-902.

4. Reya T, Morrison SJ, Clarke MF, Weissman IL. Stem cells, cancer, and cancer stem cells. Nature. 2001;414(6859):105-111.

5. Rossi DJ, Jamieson CH, Weissman IL. Stems cells and the pathways to aging and cancer. Cell. 2008;132(4):681-696.

6. Singh SK, et al. Identification of a cancer stem cell in human brain tumors. Cancer Res. 2003;63(18):5821-5828.

7. Wang JC, Dick JE. Cancer stem cells: lessons from leukemia. Trends Cell Biol. 2005;15(9):494-501.

8. Molofsky AV, Pardal R, Morrison SJ. Diverse mechanisms regulate stem cell self-renewal. Curr Opin Cell Biol. 2004;16(6):700-707.

9. Reya $\mathrm{T}$, et al. A role for Wnt signalling in self- renewal of haematopoietic stem cells. Nature. 2003;423(6938):409-414.

10. Taipale J, Beachy PA. The Hedgehog and Wnt signalling pathways in cancer. Nature. 2001;411(6835):349-354.

11. Zhao C, et al. Loss of beta-catenin impairs the renewal of normal and CML stem cells in vivo. Cancer Cell. 2007;12(6):528-541.

12. Lessard J, Sauvageau G. Bmi-1 determines the proliferative capacity of normal and leukaemic stem cells. Nature. 2003;423(6937):255-260.

13. Park IK, et al. Bmi-1 is required for maintenance of adult self-renewing haematopoietic stem cells Nature. 2003;423(6937):302-305.

14. Molofsky AV, He S, Bydon M, Morrison SJ, Pardal R. Bmi-1 promotes neural stem cell selfrenewal and neural development but not mouse growth and survival by repressing the p16Ink4a and p19Arf senescence pathways. Genes Dev. 2005;19(12):1432-1437.

15. Lowe SW, Sherr CJ. Tumor suppression by Ink4aArf: progress and puzzles. Curr Opin Genet Dev. 2003;13(1):77-83.

16. Yilmaz $\mathrm{OH}$, et al. Pten dependence distinguishes haematopoietic stem cells from leukaemia-initiating cells. Nature. 2006;441(7092):475-482.

17. Ito $\mathrm{K}$, et al. PML targeting eradicates quiescent leukaemia-initiating cells. Nature. 2008;453(7198):1072-1078.

18. Neviani P, et al. The tumor suppressor PP2A is functionally inactivated in blast crisis CML through the inhibitory activity of the BCR/ABL-regulated SET protein. Cancer Cell. 2005;8(5):355-368.

19. Chen Y, Hu Y, Zhang H, Peng C, Li S. Loss of the Alox 5 gene impairs leukemia stem cells and prevents chronic myeloid leukemia. Nat Genet. 2009;41(7):783-792.

20. Naka K, et al. TGF- $\beta$-FOXO signalling maintains leukaemia-initiating cells in chronic myeloid leukaemia. Nature. 2010;463(7281):676-680.

21. Ito $\mathrm{T}$, et al. Regulation of myeloid leukaemia by the cell-fate determinant Musashi. Nature. 2010;466(7307):765-768.

22. Bonnet D, Dick JE. Human acute myeloid leukemia is organized as a hierarchy that originates from a primitive hematopoietic cell. Nat Med. 1997;3(7):730-737.

23. Lapidot $\mathrm{T}$, et al. A cell initiating human acute 
myeloid leukaemia after transplantation into SCID mice. Nature. 1994;367(6464):645-648.

24. Dierks C, et al. Expansion of Bcr-Abl-positive leukemic stem cells is dependent on Hedgehog pathway activation. Cancer Cell. 2008;14(3):238-249.

25. Zhao C, et al. Hedgehog signalling is essential for maintenance of cancer stem cells in myeloid leukaemia. Nature. 2009;458(7239):776-779.

26. Hu Y, Swerdlow S, Duffy TM, Weinmann R, Lee FY, Li S. Targeting multiple kinase pathways in leukemic prognitors and stem cells is essential for improved treatment of $\mathrm{Ph}+$ leukemia in mice. Proc Natl Acad Sci U S A. 2006;103(45):16870-16875.

27. Hu Y, Chen Y, Douglas L, Li S. $\beta$-Catenin is essential for survival of leukemic stem cells insensitive to kinase inhibition in mice with BCR-ABLinduced chronic myeloid leukemia. Leukemia. 2009;23(1):109-116.

28. Graham SM, et al. Primitive, quiescent, Philadelphia-positive stem cells from patients with chronic myeloid leukemia are insensitive to STI571 in vitro. Blood. 2002;99(1):319-325.

29. Marley SB, Deininger MW, Davidson RJ, Goldman JM, Gordon MY. The tyrosine kinase inhibitor STI571, like interferon- $\alpha$, preferentially reduces the capacity for amplification of granulocyte-macrophage progenitors from patients with chronic myeloid leukemia. Exp Hematol. 2000;28(5):551-557.

30. Klein RF, et al. Regulation of bone mass in mice by the lipoxygenase gene Alox15. Science. 2004;303(5655):229-232.

31. Kuhn H, O'Donnell VB. Inflammation and immune regulation by 12/15-lipoxygenases. Prog Lipid Res. 2006;45(4):334-356.

32. Middleton MK, et al. Identification of 12/15-lipox- ygenase as a suppressor of myeloproliferative disease. JExp Med. 2006;203(11):2529-2540.

33. Mahipal SV, et al. Effect of 15-lipoxygenase metabolites, 15-(S)-HPETE and 15-(S)-HETE on chronic myelogenous leukemia cell line K-562: reactive oxygen species (ROS) mediate caspase-dependent apoptosis. Biochem Pharmacol. 2007;74(2):202-214.

34. Peng C, et al. Inhibition of heat shock protein 90 prolongs survival of mice with BCR-ABL-T315Iinduced leukemia and suppresses leukemic stem cells. Blood. 2007;110(2):678-685.

35. Kinder M, et al. Hematopoietic stem cell function requires 12/15-lipoxygenase-dependent fatty acid metabolism. Blood. 2010;115(24):5012-5022.

36. Pelletier SD, Hong DS, Hu Y, Liu Y, Li S. Lack of the adhesion molecules P-selectin and intercellular adhesion molecule-1 accelerate the development of BCR/ABL-induced chronic myeloid leukemia-like myeloproliferative disease in mice. Blood. 2004;104(7):2163-2171.

37. Sullivan C, et al. Functional ramifications for the loss of P-selectin expression on hematopoietic and leukemic stem cells. PLoS One. 2011;6(10):e26246.

38. Corbin AS, et al. KIT signaling governs differential sensitivity of mature and primitive $\mathrm{CML}$ progenitors to tyrosine kinase inhibitors. Cancer Res. 2013;73(18):5775-5786.

39. Goff DJ, et al. A Pan-BCL2 inhibitor renders bone-marrow-resident human leukemia stem cells sensitive to tyrosine kinase inhibition. Cell Stem Cell. 2013;12(3):316-328.

40. Pellicano F, Copland M, Jorgensen HG, Mountford J, Leber B, Holyoake TL. BMS-214662 induces mitochondrial apoptosis in chronic myeloid leukemia (CML) stem/progenitor cells, including $\mathrm{CD} 34^{+} 38^{-}$cells, through activation of protein kinase C $\beta$. Blood. 2009;114(19):4186-4196.

41. Peng C, et al. LSK derived LSK- cells have a high apoptotic rate related to survival regulation of hematopoietic and leukemic stem cells. PLoS One. 2012;7(6):e38614.

42. Peng $\mathrm{C}$, et al. PTEN is a tumor suppressor in CML stem cells and BCR-ABL-induced leukemias in mice. Blood. 2010;115(3):626-635.

43. Wymann MP, Schneiter R. Lipid signalling in disease. Nat Rev Mol Cell Biol. 2008;9(2):162-176.

44. Radich JP, et al. Gene expression changes associated with progression and response in chronic myeloid leukemia. Proc Natl Acad Sci US A. 2006;103(8):2794-2799.

45. Li S, Ilaria RL, Ilaria RL Jr, Million RP, Daley GQ Van Etten RA. The P190, P210, and p230 forms of the BCR/ABL oncogene induce a similar chronic myeloid leukemia-like syndrome in mice but have different lymphoid leukemogenic activity. J Exp Med. 1999;189(9):1399-1412.

46. Hu Y, et al. Requirement of Src kinases Lyn, Hck and Fgr for BCR-ABL1-induced B-lymphoblastic leukemia but not chronic myeloid leukemia. Nat Genet. 2004;36(5):453-461.

47. Li S, Couvillon AD, Brasher BB, and Van Etten RA. Tyrosine phosphorylation of Grb2 by Bcr/Abl epidermal growth factor receptor: a novel regulatory mechanism for tyrosine kinase signaling. ЕМВО J. 2001;20(23):6793-6804.

48. Zhang $\mathrm{H}$, et al. The Blk pathway functions as a tumor suppressor in chronic myeloid leukemia stem cells. Nat Genet. 2012;44(8):861-871. 